\title{
Combined Polyhexamethylene Quanidine and Nanocellulose for the Conservation and Enhancement of Ancient Paper
}

Xiaochun Ma

SCUT: South China University of Technology

Shenglong Tian

SCUT: South China University of Technology

Xiaohong Li

Guangzhou Paper Co.,Ltd

Huiming Fan

SCUT: South China University of Technology

Shiyu Fu ( $\nabla$ shyfu@scut.edu.cn )

SCUT https://orcid.org/0000-0001-5680-7493

\section{Original Research}

Keywords: ancient books, mildew resistance, reinforcement, strength , aging resistance

Posted Date: February 17th, 2021

DOI: https://doi.org/10.21203/rs.3.rs-200774/v1

License: (c) (i) This work is licensed under a Creative Commons Attribution 4.0 International License. Read Full License 


\section{Combined polyhexamethylene guanidine and}

\section{2 nanocellulose for the conservation and enhancement}

\section{3 of ancient paper}

4 Xiaochun $\mathrm{Ma}^{\mathrm{a}}$, Shenglong Tian ${ }^{\mathrm{a}}$, Xiaohong $\mathrm{Li}^{\mathrm{b}}$, Huiming Fan ${ }^{\mathrm{a}}$, Shiyu Fu ${ }^{\mathrm{a}, *}$

5 Contact information: State Key Laboratory of Pulp and Paper Engineering, Lingnan

6 Literature Preservation Research Center, South China University of Technology,

7 Guangzhou 510640, China; *Corresponding author: shyfu@scut.edu.cn

$8 \quad{ }^{a}$ State Key Laboratory of Pulp and Paper Engineering, South China University of

9 Technology, Guangzhou 510640,18742057146@163.com (X.M.);

10 slonet623@163.com (S.T.); hmfan@scut.edu.cn.

11 buangzhou Paper Co., Ltd, Guangzhou 510280, lixiaohong@gzpaper.cn.

$12{ }^{*}$ Corresponding author. Tel.: +13570017263. Email address: shyfu@ scut.edu.cn

13 Abstract Here a new reinforcement and mold-resistant method for ancient books is proposed based on

14 the suspension of nanocellulose $\left(\mathrm{CNC}_{\mathrm{S}}\right)$ and polyhexamethylene guanidine (PHMG). The paper

15 documents were treated with the reinforcement suspension under the optimum ratio obtained by

16 response surface methodology (RSM), then tested for mildew resistance and accelerated aging

17 experiments to evaluate the anti-mildew effect, mechanical strengthening properties and durability of

$18 \mathrm{CNC}_{\mathrm{S}} / \mathrm{PHMG}$ compound solution on ancient books. The results showed the mechanical properties of

19 the paper treated by $\mathrm{CNC}_{S} / \mathrm{PHMG}$ were significantly improved at the optimum ratio $(0.3 \mathrm{wt} \%: 0.3 \mathrm{wt} \%)$,

20 with the folding endurance increased by 1.78 times and the increase ratio of tensile strain was $46.62 \%$.

21 Meanwhile, the treated paper maintained the same good zero-span tensile strength after aging 7 days as

22 the sample unaged untreated, indicating superior aging resistance of this treatment method. In addition,

23 excellent biocidal activity with the growth trace of mold less than $10 \%$ was observed on treated paper.

24 In conclusion, it is a method that simple to operate, which can be a promising treatment of

25 conservation and enhancement of ancient paper.

26 Keywords ancient books $\cdot$ mildew resistance $\cdot$ reinforcement strength -aging

27 resistance 


\section{Introduction}

31 Ancient literatures are an important historical and cultural heritage with great

32 collection and academic value. The main form of them was made of paper, which as

33 the mainstream carrier of literatures is usually passed down to the present through

34 writing and printing. According to statistics, the literatures in collections of China

35 now reaches 30 million volumes (Wang 2006). However, due to the irregular

36 preservation conditions, such as changes of environment and inherent instability of

37 the paper itself, literatures are damaged to different degrees in the process of

38 preservation, which damage the valuable information (He et al. 2019). Therefore, it is

39 urgent for the enhancement of the paper documents.

40 Ancient books are damaged by various reasons, such as acidic substances absorbed

41 from air, additives added during paper-making and mold attacking. Actually, all those

42 factors may cause the fiber degradation, an important intrinsic factor during paper

43 aging. Acidic substances derived from the absorption of pollutants (NOx) and

44 oxidation of additives (Isca et al. 2018) can result in the fracture of fiber-glucoside

45 bond, significantly weaken the mechanical strength of paper (Erhardt 1995; Simona

46 Margutti 2001). Mold is another threat for ancient books, which possess strong

47 adaptability and rapid reproduction, producing acidic byproducts on the surface of

48 paper (Sarantopoulou et al. 2006) that depolymerized cellulose fibers (Piantanida et

49 al. 2006; Ponce-Jimenez 2003). In addition, harmful mycotoxins produced by some

50 mold may harm people's health (Konkol et al. 2012).

51 To address the reinforcement and mildew resistance of ancient books, several

52 strategies have been developed in recent years. The enhancement techniques could be

53 summarized as composite reinforcement, synthetic reinforcement and natural

54 reinforcement, according to the type of enhancement materials (Zhang 2020).

55 Generally, the synthetic materials mainly include silane coupling agent and 
56 polyurethane, etc. 3-aminopropyl-diethoxymethylsilane (AMDES) and aminopropyl

57 triethoxy silane (APTES) cause a polymer network, which forms a cross-linking

58 effect with the paper's fiber molecules to achieve reinforcement effect on newsprint

59 (Piovesan et al. 2018). The pure cellulose paper was treated by the synthetic material

60 AMDES with the tensile strength and folding resistance significantly improved

61 (Dupont et al. 2010). Composite materials usually combined natural materials with

62 synthetic materials to strengthen paper (Zhang 2020). TMSC-Mg(OH) $)_{2}-\mathrm{HMDSO}$

63 reinforcement solution is formed by uniformly dispersing trimethylsilyl cellulose

64 (TMSC) in hexamethyldisiloxane (Amornkitbamrung et al. 2015). However, there are

65 many problems such as poor polymer stability and inferior compatibility with paper

66 fibers in composite and synthetic materials. In contrast, natural materials (chitosan

67 (Li et al. 2017), guar gum, cellulose (Kukharenko et al. 2014), etc.) play an important

68 role in the protection of ancient books due to the extensive sources, friendliness to

69 environment and good compatibility with paper. Among these, nanocellulose have

70 emerged as a promising reinforcement material relying on its own unique superiority,

71 such as optical transparency (Jia 2013), excellent biocompatibility, high specific

72 surface area (Yuri Kobayashi 2015) and colloidal dispersion stability (Xiao et al.

73 2020). Ancient paper is treated by $\mathrm{CNC}_{S}$ with a striking improvement in strength,

74 which have confirmed by many reports in the past decades (Bergamonti et al. 2020).

75 Mildewproof of paper is mainly carried out by treating with Ag nanoparticles (Dai

76 et al. 2017), $\mathrm{TiO}_{2}$, chitosan (Salama et al. 2020), quaternary ammonium salt (He et al.

77 2019). Anyway, there are a lot of shortcomings such as high price, inferior

78 antibacterial ability and poor chemical stability. Recently, guanidine cationic

79 polymers attracting considerable attention due to their high biocidal activity (anti-

80 fungal (Zhang 1999), antiviral (Pinto et al. 2010; Thakkar 2009), antibacterial

81 (Manetti et al. 2009; Qian et al. 2008) and low toxicity (Zhang 1999) to the human

82 body). In particularly, the antibacterial rate of polyhexamethylene guanidine 
83 hydrochloride (PHMG) reached more than 90\% while its concentration was only 1

84 ppm (Feiertag 2003). Due to its strongly positive charges, the cationic oligomers were

85 electrostatically bonded with the negatively charged bacterial envelope, changing the

86 phospholipid environment on the cell membrane (Feiertag 2003), resulting the

87 destroy of membrane, infiltration of bacterial cell components, and death of bacteria

88 (Brogden 2005; Oule et al. 2008; Qian et al. 2008).

89 The positive PHMG can form electrostatic attraction with the negative fibers,

90 which may contribute to the formation of the hydrogen bonds between chloride ions

91 of the PHMG and the hydroxyl of the nanocellulose (Kukharenko et al. 2014), thus

92 improve the mechanical properties of paper. In view of the preservation and

93 reinforcement of ancient books, we combined PHMG and $\mathrm{CNC}_{\mathrm{S}}$ to strengthen paper.

94 PHMG was dispersed in the suspension of $\mathrm{CNC}_{\mathrm{S}}$ to form a compound solution, and

95 then sprayed on the surface of the paper with the spray gun. The paper documents

96 were processed under the optimal conditions explored by response surface

97 methodology (RSM) to obtain the strengthening and anti-mildew properties.

98 Experimental Methods

99 Materials

100 Polyhexamethylene guanidine hydrochloride (PHMG) was purchased from

101 Macklin Biochemical Technology Co., LTD. Sulfuric acid was purchased from

102 Guangzhou chemical reagent factory. Hardwood dissolving pulp was supplied by

103 Huatai paper Co., LTD (Shandong China). Paper samples were taken from the

104 Whatman paper and an old book that published in 1954, respectively. 
106 CNCs was prepared from hardwood dissolving pulp hydrolyzed by $55 \mathrm{wt} \%$ sulfuric

107 acid applied at $45{ }^{\circ} \mathrm{C}$ for 40 min according to the reported work of our group (Peng et

108 al. 2018). The length of the CNCs was between 40 and $800 \mathrm{~nm}$, while the diameter

109 was $10 \sim 20 \mathrm{~nm}$. $\mathrm{CNC}_{\mathrm{S}}$ suspensions $(1 \% \mathrm{w} / \mathrm{v})$ were diluted to different concentrations

$110(0.1 \sim 0.5 \mathrm{wt} \%)$ and mixed with PHMG to obtain $\mathrm{CNC}_{S} /$ PHMG compound solution.

\section{Experimental design and optimization}

\section{Design of the response surface methodology}

113 The Whatman paper samples $(\mathrm{d}=18 \mathrm{~cm})$ were treated with $\mathrm{CNC}_{\mathrm{S}} / \mathrm{PHMG}$ of

114 different concentrations in the early stage of this study. The processed paper was

115 dried naturally in the air and then transferred to a vacuum drying oven (0.08 $\mathrm{MPa}$,

$\left.11650{ }^{\circ} \mathrm{C}\right)$ for $12 \mathrm{~h}$. The weight percentage gain was $2.30 \%( \pm 0.59)$ on average.

117 A response surface methodology (RSM) was used to investigate the effect of the

118 concentrations of $\mathrm{CNC}_{\mathrm{S}}(\mathrm{A})$ and PHMG (B) on paper's mechanical properties.

119 The experimental design factors and horizontal pieces were shown in Table 1. The 120 tearing index (Y) of the treated paper samples was taken as the response value.

121 Equation (1) was used to calculate the enhanced percentage $(\mathrm{P})$ of tearing strength:

$$
P=\frac{Y_{\text {treated }}-Y_{\text {untreated }}}{Y_{\text {untreated }}} \times 100
$$

123 Where $Y_{\text {treated }}$ and $Y_{\text {untreated }}$ are the tearing index of treated and untreated samples, 124 respectively.

125 According to the Central Composite Design method (CCD) provided by design126 Expert 8.0.6 statistical software, thirteen experimental runs were required, which 127 included five replicates of the central run (Jalali and Sobati 2017). 
Table 1 Experimental design factors and levels

\begin{tabular}{ccccccc}
\hline Factors & Name & Units & Low & High & -alpha & +alpha \\
\hline A & CNF & $\%$ & 0.1 & 0.5 & 0.017153 & 0.582843 \\
B & PHMG & $\%$ & 0.1 & 0.5 & 0.017153 & 0.582843 \\
\hline
\end{tabular}

129 The quadratic polynomial regression equation obtained by using the design-Export

130 software to correlate the strengthening process of paper:

$$
Y=b_{0}+b_{1} A+b_{2} B-b_{12} A B-b_{1}{ }^{2} A^{2}-b_{2}{ }^{2} B^{2}
$$

132 Where $Y$ is the predicted response (i.e., the tearing index); $A, B$ are coded levels of 133 independent variables; the coefficients of linear effect, quadratic effect and 134 interaction effect are respectively represented by bi,bii,bij (Wang et al. 2015).

\section{The repair process of ancient book}

136 The $\mathrm{CNC}_{\mathrm{S}} / \mathrm{PHMG}$ suspension was sprayed evenly onto the paper $(17.5 \times 14 \mathrm{~cm})$

137 published in 1954 at the optimum ratio that derived from the RSM. $10 \mathrm{ml}$ of the

138 suspension was used to spray twice on paper with an interval of 20 min (Bergamonti

139 et al. 2020). The processed paper samples were naturally dried at room temperature

140 for $6 \sim 7 \mathrm{~h}$ and then transferred to a vacuum drying oven $\left(0.08 \mathrm{MPa}, 50{ }^{\circ} \mathrm{C}\right)$ for $12 \mathrm{~h}$.

141 The weight percentage gain of samples was $2.70 \%( \pm 0.113)$ on average.

\section{$142 \quad$ Artificial aging experiment}

143 According to the standard of GB/T 22894-2008, the aging experiment of the

144 treated and untreated paper was carried out to simulate the natural aging process and

145 evaluate the anti-aging performance. The samples were aged under the conditions of $14680{ }^{\circ} \mathrm{C}$ and $65 \% \mathrm{RH}$ for certain days. 


\section{Characterization and measurements}

\section{Mechanical tests}

149 The properties of paper samples were tested under the certain condition of $25^{\circ} \mathrm{C}$,

$15050 \% \mathrm{RH}$ after balancing moisture for $24 \mathrm{~h}$ (ISO1871990). Ten samples were tested for

151 each group and each sample was measured in parallel five times, the results were

152 averaged.

153 Tensile strength of paper $(15 \times 100 \times 0.08 \mathrm{~mm})$ were determined by universal testing 154 machine (INSTRON 3300) (30mm/min) accordance with ISO 1924-2:2008 standards.

155 Tearing strength were measured by the instrument (L\&W009, Sweden) according to

$156 \mathrm{~GB} / \mathrm{T} 455-2002$. The size of the samples was $(63 \pm 0.5) \mathrm{mm} \times(50 \pm 2) \mathrm{mm}$. In order to

157 ensure the accuracy of the test, paper samples were selected according to GB/T-450

158 to avoid wrinkles and other defects. The zero-span tensile strength measurements on

159 samples were carried out according to GB/T 26460-2011 standards with the

160 instrument (L\&W CE062, Sweden) $(25 \pm 2$ N/s). Paper samples were tested in parallel

161 ten times with a width of $63 \mathrm{~mm}$ and a length of $40 \sim 195 \mathrm{~mm}$. Folding Endurance

162 measurements were performed accordance with GB/T 457-2002 by a double fold

163 instrument $(\mathrm{MIT} / \mathrm{U} 21 \mathrm{~B}$, America, applied force=1.0 KN). Paper samples were cut to

$164130 \mathrm{~mm} \times 15 \mathrm{~mm}$.

\section{Brightness test}

166 The Brightness of paper was determined by L\&W Elrepho070 whiteness meter 167 according to ISO $11475-2017$ standard. Taking 5 areas of each sample for 168 measurement. CIE L*a* $\mathrm{b} *$ system was used to evaluate the color change of the 
169 paper, $\Delta \mathrm{E}$ represent the color difference, calculation formula as shown in the equation $170 \quad(3)$ :

$$
\Delta E^{*}=\sqrt{\left(\Delta L^{*}\right)^{2}+\left(\Delta a^{*}\right)^{2}+\left(\Delta b^{*}\right)^{2}}
$$

\section{SEM and XRD analysis}

173 The scanning electron microscope (SEM, Merlin) was used to observe the

174 morphology of paper. The X-ray diffractometer ( $\mathrm{X}^{\prime}$ pert Powder) was used to

175 analysis the X-ray diffraction (XRD) of samples. The crystallinity (CrI) of cellulose

176 can be calculated by equation (4):

$$
C r I=\frac{I_{002}-I_{a m}}{I_{002}} \times 100
$$

178 Where $I_{a m}$ and $I_{002}$ are the intensity of the diffraction peaks of $2 \theta=18.0^{\circ}$ and

$1792 \theta=22.5^{\circ}$, respectively.

180 anti-mold test

181 The mold-resistant experiments of paper samples were carried out by Guangdong 182 Microbiological testing Center according to the GB/T 24346-2009 and AATCC 30-

183 2013III. The paper samples were treated with four kinds of mixed mold (Aspergillus

184 Niger, Trichoderma Viride, Penicillium Funiculosum, Chaetomium Globosum) for 28

185 days and a single Aspergillus Niger with a cycle of 7 days, respectively. The original 186 paper samples were blank. 


\section{Results and Discussion}

\section{The preparation of CNCs/PHMG suspension}

189 In this study, PHMG combined with $\mathrm{CNC}_{\mathrm{S}}$ was supposed to apply for the 190 preservation and enhancement of ancient books. The $\mathrm{CNC}_{S} / \mathrm{PHMG}$ complex

191 solutions were prepared by mixing $\mathrm{CNC}_{\mathrm{S}}$ suspensions in various dilute concentrations

192 with PHMG. The concentration of $\mathrm{CNC}_{\mathrm{S}}$ and PHMG had influence on the mechanical

193 properties of paper (Yi et al. 2017). In order to investigate this interaction, RSM was

194 used to simulate the experiment to obtain the optimum treatment conditions, so as to

195 achieve the superior improvement in the mechanical strength of paper.

Model fitting and adequacy checking

197 Design of the experiment and results of the response surface are shown in Table 2.

198 Equation (5) represents the quadratic multiple regression equation, which is used to

199 fit the experimental data of tearing index of paper patterns.

$$
Y=43.58+0.56 A+0.054 B+9.11 A B-14.53 A^{2}-10.30 B^{2}
$$

201 Where $Y$ is the tearing index $\left(\mathrm{mN} \cdot \mathrm{m}^{2} / \mathrm{g}\right) ; A, B$ are the content $(\%)$ of $\mathrm{CNCs}_{\mathrm{s}}$ and 202 PHMG, respectively. The parameters have increasing and decreasing effects on the 203 response value $\mathrm{Y}$, which can be seen from the symbols and values of the coefficient 204 (Jalali and Sobati 2017).

205 Table 2 Experimental design for response surface analysis and corresponding experimental data

\begin{tabular}{cccc}
\hline \multirow{2}{*}{ Run } & \multicolumn{2}{c}{ Coded variable levels } & Response Y \\
\cline { 2 - 4 } & A & B & \\
\hline 1 & 0.10 & 0.50 & 5.66 \\
2 & 0.02 & 0.30 & 5.58 \\
3 & 0.30 & 0.30 & 7.21 \\
4 & 0.50 & 0.50 & 6.54
\end{tabular}




$\begin{array}{llll}5 & 0.50 & 0.10 & 5.52 \\ 6 & 0.30 & 0.30 & 7.57 \\ 7 & 0.30 & 0.30 & 7.06 \\ 8 & 0.30 & 0.30 & 7.31 \\ 9 & 0.30 & 0.30 & 7.20 \\ 10 & 0.30 & 0.02 & 6.17 \\ 11 & 0.30 & 0.58 & 6.04 \\ 12 & 0.10 & 0.10 & 6.48 \\ 13 & 0.58 & 0.30 & 5.79\end{array}$

206 Table 3 represents analysis of variance (ANOVA) of regression equation, that is a 207 statistical method for detecting differences between sample groups. As can be seen 208 from the Table 3, the smaller P-value and the larger F-value confirm the exists of 209 significant corresponding coefficients (Wang et al. 2015). The values of "Prob > F" 210 less than 0.0500 imply that the model is significant and the curvature is present. The 211 interaction term of $\mathrm{AB}$ is significant ("Prob $>\mathrm{F}^{\prime}$ is 0.0014 ), indicating the remarkable 212 interaction of the concentration of $\mathrm{CNC}_{\mathrm{S}}(\mathrm{A})$ and $\mathrm{PHMG}(\mathrm{B})$ on the tearing strength 213 of the samples.

Table 3 Analysis of variance of regression equation

\begin{tabular}{cccccc}
\hline Source & $\begin{array}{c}\text { Sum of } \\
\text { Squares }\end{array}$ & df & Mean Square & F Value & $\begin{array}{c}\text { p-value } \\
\text { Prob>F }\end{array}$ \\
\hline Model & 6.21 & 5 & 1.24 & 38.05 & $<0.0001$ \\
A-CNF & $5.885 \mathrm{E}-003$ & 1 & $5.885 \mathrm{E}-003$ & 0.18 & 0.6838 \\
B-PHMG & $3.261 \mathrm{E}-005$ & 1 & $3.261 \mathrm{E}-005$ & $9.993 \mathrm{E}-004$ & 0.9757 \\
$\mathrm{AB}$ & 0.85 & 1 & 0.85 & 25.94 & 0.0014 \\
$\mathrm{~A}^{2}$ & 3.95 & 1 & 3.95 & 121.11 & $<0.0001$ \\
$\mathrm{~B}^{2}$ & 2.06 & 1 & 2.06 & 63.03 & $<0.0001$ \\
Residual & 0.23 & 7 & 0.033 & & \\
Lack of fit & 0.084 & 3 & 0.028 & 0.78 & 0.5641 \\
Pure Error & 0.14 & 4 & 0.036 & & \\
Cor Total & 6.44 & 12 & & & \\
\hline
\end{tabular}

215 The coefficient of determination of the proposed correlation are shown in Table 4. 216 The regression model has high level of confidence and good adaptability in the 
217 experimental data (>96\%) (Jalali and Sobati 2017), which is confirmed by the high

218 value of the variation coefficient, the adjustment coefficient $\left(A d J \cdot R^{2}=0.9392\right)$ and the

219 low value of the coefficient of variation $(\mathrm{CV}=2.79 \%)$. The correlation coefficient $\mathrm{R}^{2}$

220 of this model is 0.9645 , which means that there are the obvious correlation of this

221 regression model and the data cannot be explained only account for $3.55 \%$

222 (Peydayesh et al. 2017). The 2.79 of the CV\% confirmed the better reproducibility of

223 the results (Rabelo et al. 2014).

Table 4 Statistical analysis of regression equation error

\begin{tabular}{cccc}
\hline Statistics project & value & Statistics project & value \\
\hline Std.Dev. & 0.18 & R-Squared & 0.9645 \\
Mean & 6.47 & Adj R-Squared & 0.9392 \\
C.V.\% & 2.79 & Pred R-Square & 0.8719 \\
\hline
\end{tabular}

225 The normal probability plot, the plot of residual versus predicted values, and the

226 chart of the actual values of the tearing index versus the predicted data are shown in 227 Fig. 1a-c, respectively.

228 The points are approximately located on a straight line in Fig. 1a, which proves the

229 normal distribution of the residual. As can be seen from the Fig.1b, the distribution of

230 these points is random and the location is in the range of \pm 3.0 , which confirmed the

231 adequacy of the empirical model (Rabelo et al. 2014). Fig.1c displays that the points

232 are clustered near the diagonal, which proves the good correlation between

233 experimental and predicted values. In conclusion, the model with effectiveness and

234 usability can effectively predict the enhancement effect of the tearing strength of 235 paper. 

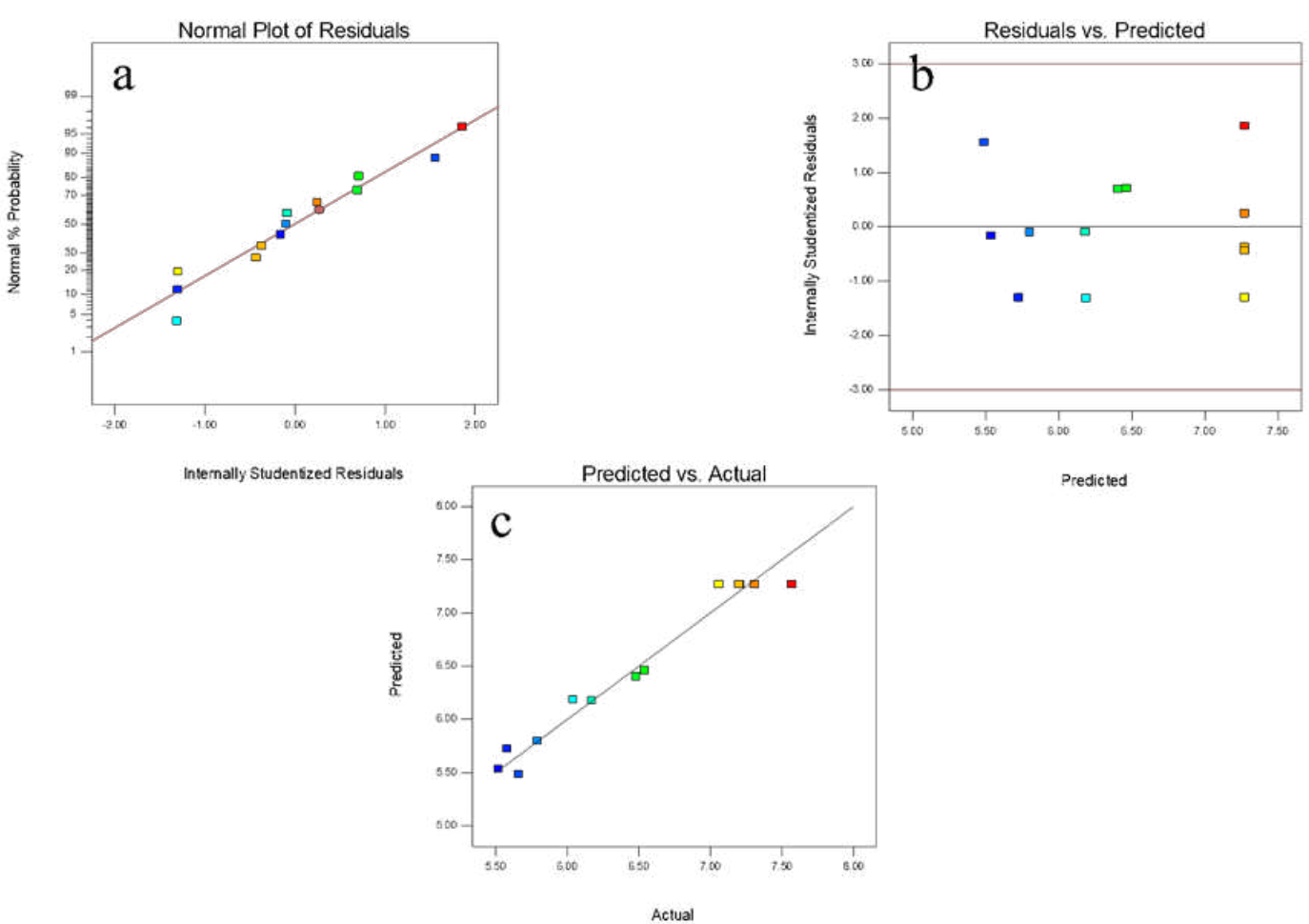

237 Fig. 1. Evaluation of RSM correlation for the paper's tearing index $\left(\mathrm{mN} \cdot \mathrm{m}^{2} / \mathrm{g}\right)$. (a) The normal 238 probability distribution of residuals, (b) Distribution of residual versus predicted values, and(c) Chart 239 of predicted value and actual value

\section{Interaction between the independent parameters}

241 Fig.2 showed the response surface diagrams of the interaction between operating 242 parameters (the concentration of $\mathrm{CNC}_{\mathrm{S}}$ and $\mathrm{PHMG}$ ) and the tearing index of paper.

243 As can be observed, the tearing strength of treated paper improved with the increase 244 of $\mathrm{CNC}_{\mathrm{S}}$ concentration $(0.10 \sim 0.30 \mathrm{wt} \%)$ and then declined in the concentration 245 between $0.30 \sim 0.50 \mathrm{wt} \%$. The effect of PHMG on the reinforcement of paper also 246 showed the same trend. This trend can be attributed to the higher concentration of 247 CNCs with the higher viscosity, more solution retained and attached to the paper, 248 which significantly improved the strength of paper. The decreasing trend can be 249 explained by the fact that $\mathrm{CNCS}_{\mathrm{S}}$ can only improve the mutual binding force between 250 fibers, but not increase the fiber length. What's more, PHMG may limit the 251 improvement effect of $\mathrm{CNC}_{\mathrm{S}}$ on the mutual binding force due to the existence of - 
$252 \mathrm{NH}_{2}$, which prevent the formation of hydrogen bonds (Liu et al. 2014; Zhong et al.

253 2013). The optimal concentration of nanocellulose on ancient books repair was about

$2540.3 \mathrm{wt} \%$, higher concentration did not bring a significant improvement in tearing

255 strength, indicate that the strengthening effect of $\mathrm{CNC}_{S}$ on aged paper is not linearly

256 increasing. The similar trends was also found in the work of Yi et al. (2017).

257 RSM suggested the optimal conditions of the above two parameters in the

258 improvement of tearing strength. According to the response surface diagrams and the

259 evaluation of the regression model, the predicted tearing index of 7.27 and the

260 enhanced percentage of $44.53 \%$ could be achieved using the suspension of $\mathrm{CNC}_{\mathrm{S}}$ and

261 PHMG (0.3wt\%:0.3wt\%). The above prediction results were verified by carrying out

262 three repeated experiments (Jalali and Sobati 2017). The tearing index was as high as

263 7.31, with an average increase of $42.5 \%$, which was basically consistent with the 264 predicted percentage of tear strength enhancement, proving the applicability and 265 reliability of the model.

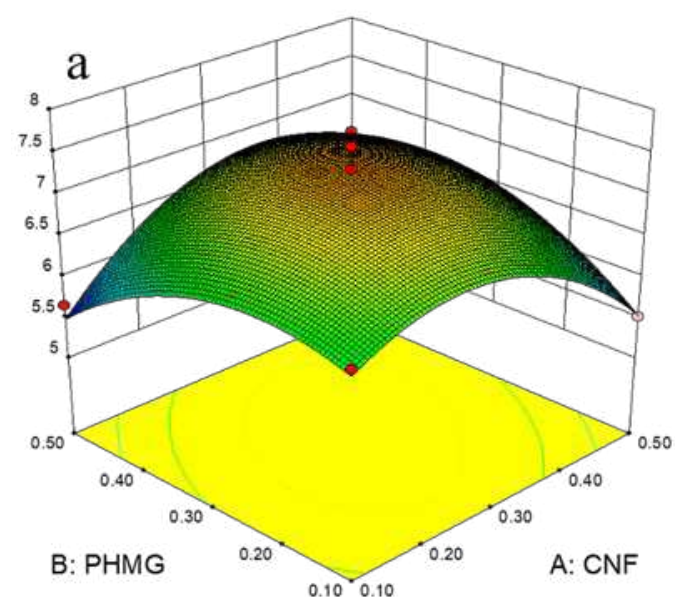

266

267

268

269

270 enhancement of tearing strength of paper samples
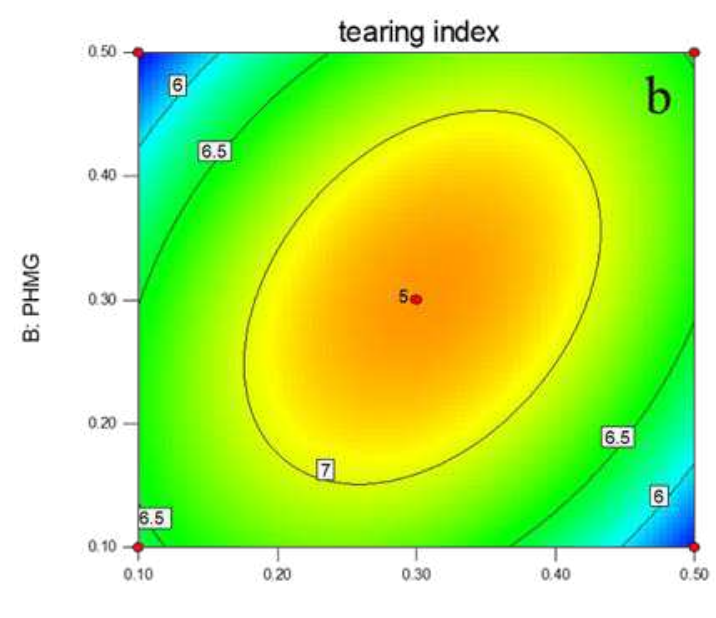

A: CNF

Fig.2. The interaction between the concentration of $\mathrm{CNC}_{\mathrm{S}}$ and the density of PHMG on the

\section{Application of CNCs/PHMG treatment on old paper samples}

Nanocellulose was applied to repair and strengthen old paper due to its superior 
271 advantages such as unique properties that similar to natural cellulose and large

272 number of hydrogen bonds formed with paper fibers (Xiao et al. 2020).

\section{Performance comparison of treated and untreated paper}

274 In this work, we combined PHMG and nanocellulose to improve the ancient

275 literature strength at the optimal ratio of $0.3 \mathrm{wt} \%$ : $0.3 \mathrm{wt} \%$, which was obtained by 276 RSM above.

277 Table 5 showed the results of chromaticity and mechanical properties of paper 278 documents before and after treatment. The original paper had a tearing index, a zero279 span tensile strength and a folding endurance of $3.61 \mathrm{mN} \cdot \mathrm{m}^{2} / \mathrm{g}, 75.0 \mathrm{KN} / \mathrm{m}$ and 5

280 times. In contrast, mechanical properties of samples were improved after treated with $281 \mathrm{CNC} / \mathrm{PHMG}$, with a significant increase (1.78 times) in folding strength and an 282 obvious improvement $(29.93 \%)$ in tearing strength, which further proves the 283 applicability of the response surface model. What's more, the tensile strain of the 284 treated sample tested on a universal material testing machine increased from $1.42 \%$ to $2852.08 \%$ with an increase ratio of $46.62 \%$, which can be observed from the Fig.3. 286 Meanwhile, the tensile strength increased by 1.10 times from the original $15.57 \mathrm{MPa}$ 287 to $17.15 \mathrm{MPa}$. The excellent mechanical properties further illustrated the considerable 288 enhancement effect of $\mathrm{CNCS}_{\mathrm{S}}$ on ancient books, which is consistent with the previous 289 research (Bergamonti et al. 2020). Nanocellulose with the similar structure to paper 290 fibers can form crossing-linking effect, strengthen the bonding network and act as the 291 adhesive between cellulose fibers (Zhang et al. 2016). The enhancement effect of $292 \mathrm{CNC}_{\mathrm{S}}$ on ancient literature may be ascribed to the formation of a large number of 293 hydrogen bonds between the fibers (Kukharenko et al. 2014). What's more, the $-\mathrm{NH}_{2}$

294 group of PHMG may also form chemical bonds with the -OH group in paper (Salam 295 et al. 2013). 
296 In addition, the surface tension and the binding force brought by water evaporation 297 can promote the combination of $\mathrm{CNC}_{\mathrm{S}}$ and paper fibers, make the fiber more tightly 298 by filling the pores, so as to achieve the enhancement on the paper literature, which 299 can also be confirmed by SEM images (Fig.4a). It can be seen the presence of lots of 300 pores and the loose dispersion of fiber, which would have a negative effect on the 301 strength of the paper. In contrast, the images of treated paper show a dense structure 302 and a smooth surface that filled the space among the fibers with nanocellulose (Zhang 303 et al. 2016), which is of great significance for the enhancement of paper's strength.

304 The $\mathrm{XRD}$ was used to evaluate the effect of $\mathrm{CNC}_{S} / \mathrm{PHMG}$ treatment on fibers 305 crystalline structure. It can be seen a slight change in peak intensity of paper samples 306 before and after treatment. The CrI of paper fibers that calculated by formula (4) were $30761.94 \%$ (UT) and $64.90 \%(\mathrm{~T})$, which indicate that the treatment did not cause an 308 obvious decline in the degree of the order for paper cellulose and had little impact on 309 the fiber.

310 Table 5 Performance comparison of untreated paper (UT) and the sample(T) treated by $\mathrm{CNC}_{\mathrm{S}} / \mathrm{PHMG}$

\begin{tabular}{ccccccc}
\hline $\begin{array}{c}\text { Paper } \\
\text { sample }\end{array}$ & $\begin{array}{c}\text { Tearing } \\
\text { strength } \\
\left(\mathrm{mN} \cdot \mathrm{m}^{2} / \mathrm{g}\right)\end{array}$ & $\begin{array}{c}\text { The zero- } \\
\text { span tensile } \\
\text { strength } \\
(\mathrm{KN} / \mathrm{m})\end{array}$ & $\begin{array}{c}\text { Folding } \\
\text { Endurance } \\
\text { (times) }\end{array}$ & Brightness & $\begin{array}{c}\text { Chromatic } \\
\text { aberration } \\
(\Delta \mathrm{E})\end{array}$ & $\begin{array}{c}\text { Tensile } \\
\text { strain } \\
(\%)\end{array}$ \\
\hline $\mathrm{UT}$ & $3.61 \pm 0.07$ & $75.00 \pm 4.25$ & $5.00 \pm 0.14$ & $39.42 \pm 0.27$ & - & 1.42 \\
$\mathrm{~T}$ & $4.69 \pm 0.28$ & $79.30 \pm 1.80$ & $5.33 \pm 0.04$ & $39.15 \pm 1.55$ & 0.47 & 2.08 \\
$\begin{array}{c}\text { Increased } \\
\text { ratio (\%) }\end{array}$ & $+29.92 \%$ & $+5.74 \%$ & $+17.12 \%$ & $-0.68 \%$ & - & $+46.62 \%$ \\
\hline
\end{tabular}

311 Note: In the table, “+” represents the percentage of increase and "-" represents the ratio of decrease 


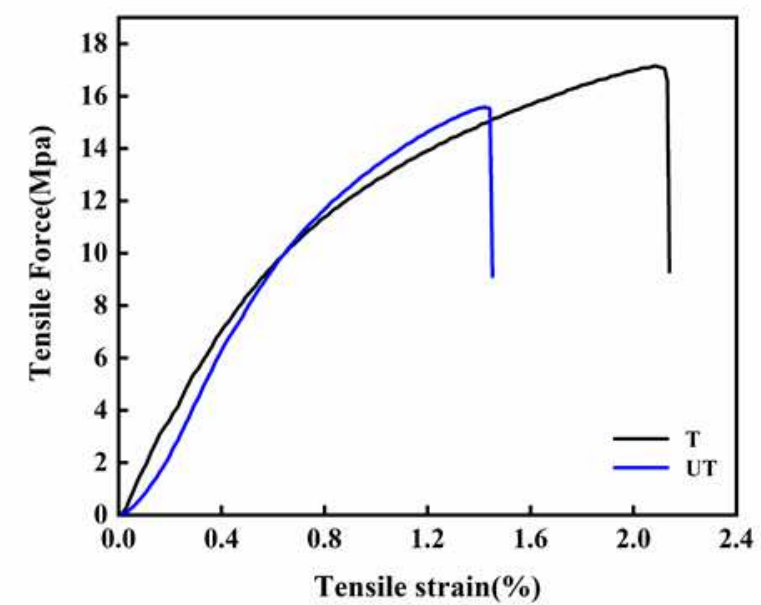

313 Fig.3. Tensile force vs. percentage tensile strain for treated and untreated paper

314 In the process of ancient books restoration, attention should also be paid to 315 minimize the impact on their appearance (He et al. 2019). The whiteness of samples 316 was tested to determine changes on the surface. These results showed a slight

317 decrease in whiteness of $0.68 \%$ and a small value in color difference $\Delta \mathrm{E}$ of 0.472 . A

318 faint decrease in brightness is not obvious to the human eye, which can be observed

319 from the photos shown in Fig.S2, indicating that this treatment of ancient books is 320 appropriate.
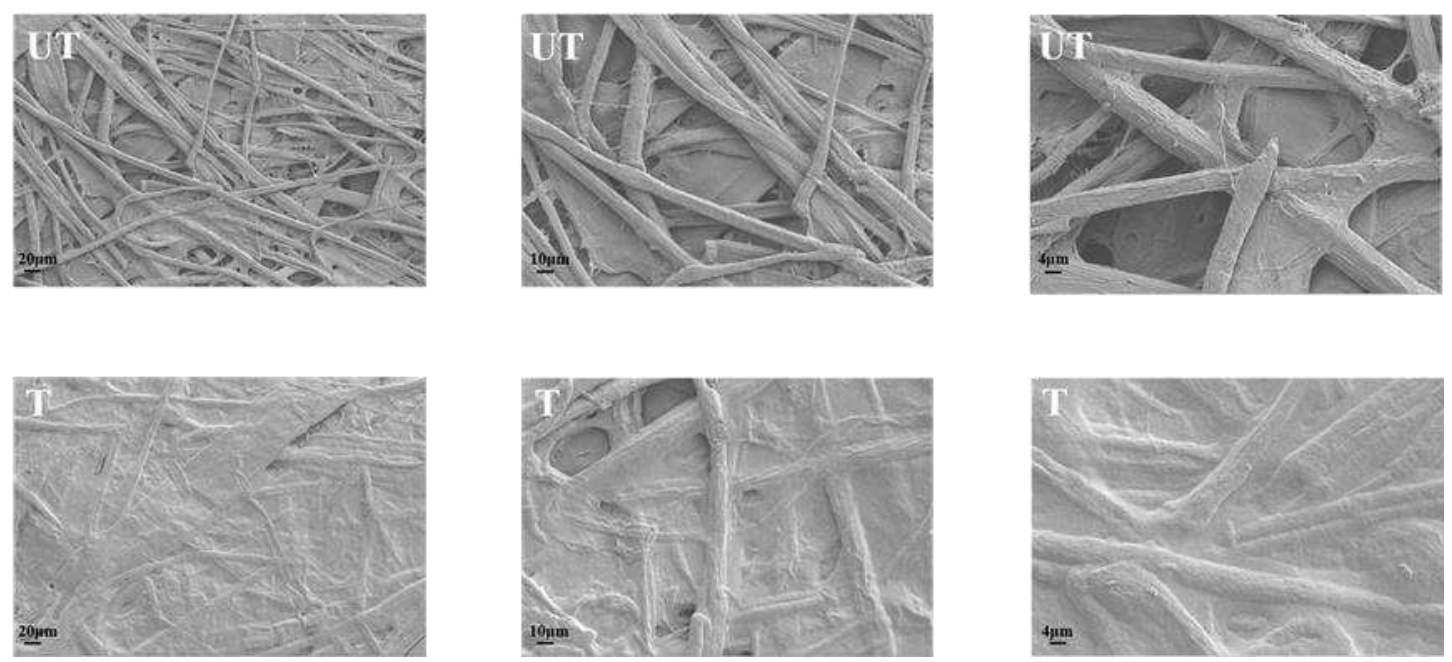

Fig. 4. (a) SEM images of these paper samples treated (T) and untreated (UT) 

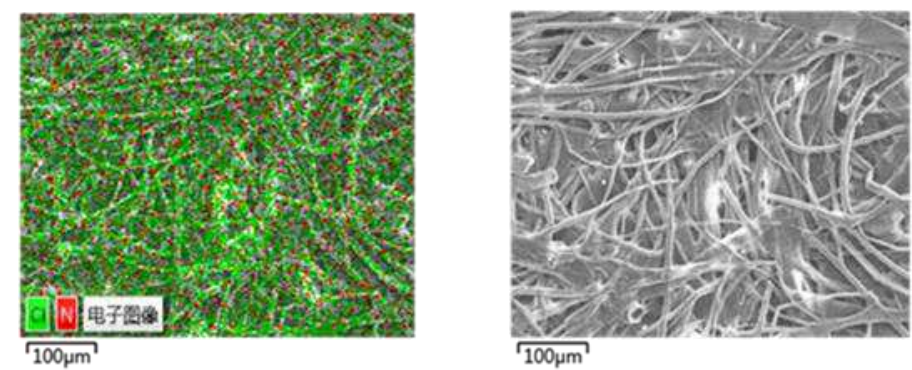

$\mathrm{CI} \mathrm{K \alpha 1}$
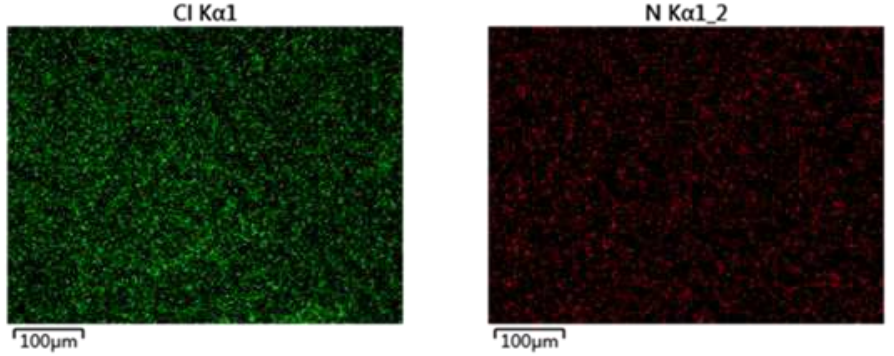

Fig. 4. (b) SEM-EDS images of the paper sample treated by $\mathrm{CNC}_{S} / \mathrm{PHMG}$

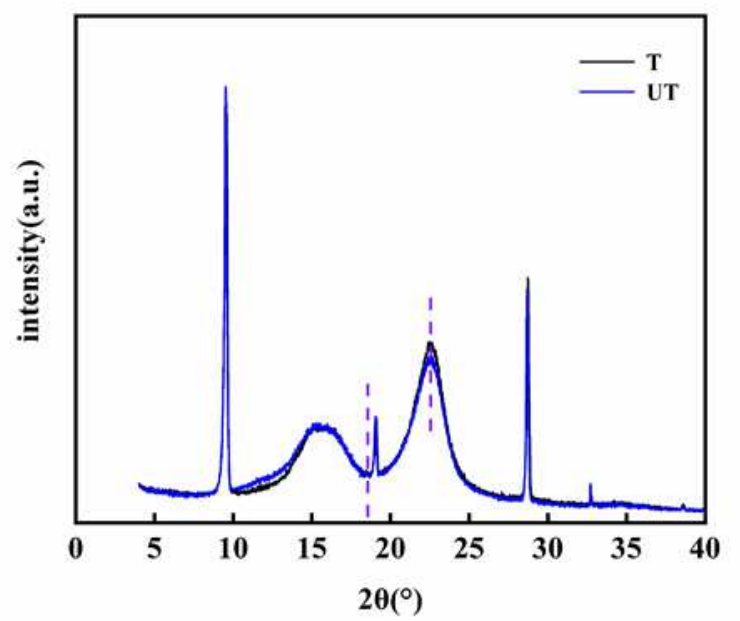

327 Comparison of anti-aging property

328 In order to better assess the stability and anti-aging properties of the treatment

329 with $\mathrm{CNC}_{\mathrm{S}} / \mathrm{PHMG}$ suspension, paper samples were subsequently artificially aged for

330 a certain time in the same conditions.

331 Fig.6 showed a similar decline trend in mechanical properties of the treated

332 paper and untreated group after 3, 5, 7 and 9 days of aging, in which the folding 
333 strength of the untreated paper declined sharply. The ancient paper's aging rate was

334 faster within the aging time of 0 5 days, which mainly due to the acid substance that 335 produced in the aging process degraded cellulose, reduced the degree of 336 polymerization of fiber, thus result in a rapid decline in fiber strength(Erhardt 1995).

337 The strength of treated sample was much better than its untreated aged counterpart,

338 which indicates the obvious protective effect against the properties decline of this

339 treatment. What's more, the treated paper samples still exhibited the same good zero-

340 span tensile strength as the paper untreated unaged that can be observed from 7 days

341 of aging. The zero-span tensile strength reflects the fiber strength (Zeng 2012). The

342 fiber strength of the treated aged paper samples is higher than that of the untreated 343 aged counterpart, which further indicates the stability of the treatment by $344 \mathrm{CNC}_{\mathrm{S}} / \mathrm{PHMG}$.
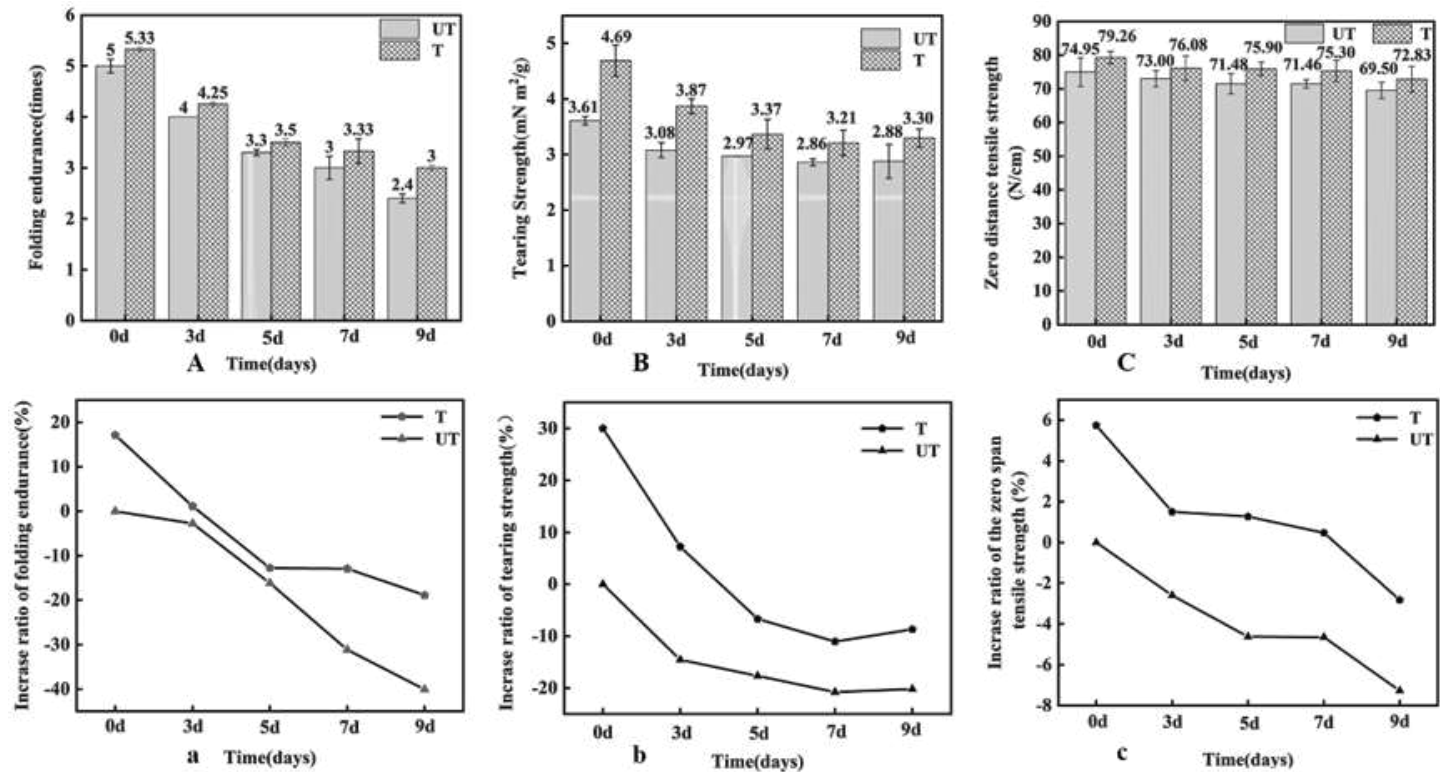

345

346

347

348

349

350

351

352

Fig.6. The comparison of treated and untreated paper samples after aging on folding endurance (A); tearing index(B) and zero-span tensile strength(C); Enhanced ratio comparison: folding endurance (a), tearing strength(b) and zero-distance tensile strength(c)

The XRD pattern of the paper fibers before and after accelerated aging is shown in Fig.S1, which can be found in supporting information. The CrI of treated and untreated samples changed slightly, indicating that the treatment method has subtle influence on the fiber structure even after a certain time of aging. 
353 The whiteness and chromatic aberration $(\Delta \mathrm{E})$ of aged paper was also examined 354 which is showed in Fig.7, detailed data can be found in Table S1. It can be seen the 355 same decreasing trend of treated and untreated paper samples in brightness with the 356 aging time extended, which may be due to the oxidation reaction of the paper fibers 357 during the damp-heat aging process, resulting in the generation of colored aldehyde 358 group (Fan and Guo 2018). The treatment method had little impact on the surface of 359 paper samples with only a slight difference in brightness (UT 35.11\%, T 34.94\%) 360 even aged for 9 days.

361

362

\section{Anti-mold property}

364 In addition to the enhancement of strength, improving the mildew resistant 365

368 Oule et al. 2008). Paper obtained by dip-coating with modified guanidine-based

369 particle aqueous dispersion (PHGH-PPGDE) exhibits 100\% antibacterial rate against

370 Escherichia coli (Wei et al. 2017). 
371 To investigate the anti-mildew effect and the stability, the biocidal activity on four 372 mixed mold (Aspergillus Niger, Trichoderma Viride, Penicillium Funiculosum, 373 Chaetomium Globosum) and a single Aspergillus Niger were verified on paper 374 treated by $\mathrm{CNC}_{\mathrm{S}} / \mathrm{PHMG}$ and the original paper with a cycle of 28 days and 7 days, 375 respectively. Fig.8 showed the result of 7-days anti-Aspergillus Niger activity. 376 Obvious fungal growth can be seen on the untreated paper, indicating the lack of 377 antifungal activity for ancient literature. In contrast, a significant biocidal activity on

378 treated sample was observed, with the generation of a mold proof circle and no mold 379 growth in the surface which confirmed the importance of PHMG in mold-proof 380 treatment. Similar results were found in the study of Liu et al. (2014), the paper 381 coated with DCMC-GH exhibit remarkable bacteriostatic effect on Escherichia coli 382 and Staphylococcus aureus, with inhibition zone of $16 \mathrm{~mm}$ and $10 \mathrm{~mm}$, respectively. 383 The photos of the 28-days anti-mixed fugus results were showed in Fig.9. We also 384 observed the paper surface to see the growth state of mold by a polarizing microscope 385 at a magnification of 50 times. It can be seen small amounts of fungus on the surface 386 of treated paper, whereas the original sample with more mold growth and even 387 generated colonies that distributed in rows. Detailed antibacterial analysis and test 388 results showed in the report, which can be found in supporting information. As shown 389 in the report, with the treatment of PHMG a stronger antifungal activity can be 390 observed, mold is rarely and the traces of growth less than $10 \%$ in the treated paper 391 sample.

392 As can be seen from the above, such a superior antifungal property was attributed 393 to the evenly disperse of PHMG on paper surface, which can be observed from the 394 SEM-EDS in the Fig.3b. The PHMG with strongly positive charges can quickly bind 395 to the surface of the negative fungus, damage the cell membrane, thus achieve the 396 inhibition of the mold growth (Zhang 1999). The anti-mold test results of 7-days in 397 the single fungi and 28-days in four mixed mold fungus confirmed the significant 
398 mildew proof effect and long-term effectiveness of $\mathrm{CNC}_{\mathrm{S}} / \mathrm{PHMG}$ treatment, which is 399 of great significance for the preservation and protection of ancient books.

400


401 Fig.8. The 7-days anti-Aspergillus Niger effect of paper samples:(1) A UT (untreated) (2) B T (treated) 

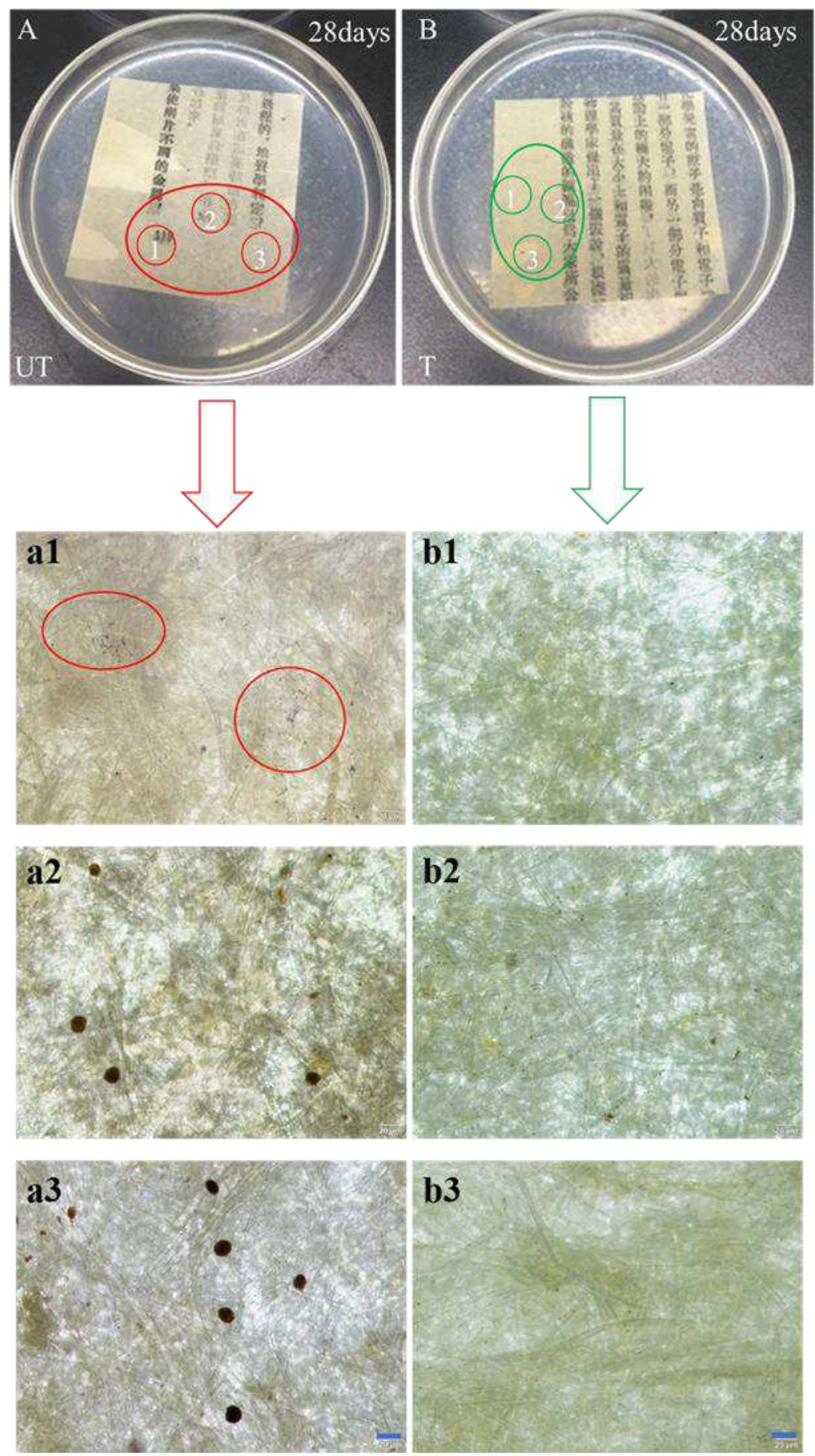


\section{Conclusion}

406 The protection of paper documents is very important in the area of cellulosic 407 material. Polyhexamethylene guanidine (PHMG) and $\mathrm{CNC}_{\mathrm{S}}$ were used to achieve the 408 enhancement and mold-proof of ancient books. RSM was employed to optimize the 409 experimental conditions to get the optimal ratio of the compound solution for paper 410 reinforcement. Mechanical tests demonstrated the enhancement of paper treated by $411 \mathrm{CNC}_{\mathrm{S}} / \mathrm{PHMG}$, with 1.78 times improvement of the folding strength, which was 412 mainly caused by the interaction between $\mathrm{CNC}_{S}$ and paper fibers. Meanwhile, the 413 treated paper with slight change on the whiteness still maintained good mechanical 414 properties after a period of aging. In addition, excellent biocidal activity was 415 observed on treated paper. To the final summary, this treatment approach gives the 416 paper excellent anti-aging performance and superior anti-mildew effect with the 417 significant improvement of the mechanical properties, which is conducive for the 418 long-term preservation and protection of ancient books.

419 Acknowledgements This work was financially supported by Science and Technology Plan Special 420 Project of Guangzhou, China (No. GZDD201808) and the National Natural Science Foundation of 421 China (31570569).

\section{References}

423 Amornkitbamrung L et al. (2015) Polysaccharide stabilized nanoparticles for deacidification and $424 \quad$ strengthening of paper. RSC Advances. 5:32950-32961.https://doi.org/:10.1039/c4ra15153d

425 Bergamonti L et al. (2020) Ag-functionalized nanocrystalline cellulose for paper preservation and 426 strengthening. Carbohydr Polym. 231:115773.https://doi.org/:10.1016/j.carbpol.2019.115773

427 Brogden KA (2005) Antimicrobial peptides: pore formers or metabolic inhibitors in bacteria? Nat Rev 428 Microbiol. 3:238-250.https://doi.org/:10.1038/nrmicro1098

429 Dai L, Liu R, Hu LQ, Si CL (2017) Simple and green fabrication of AgCl/Ag-cellulose paper with 430 antibacterial and photocatalytic activity. Carbohydr Polym. 174:450431 455.https://doi.org/:10.1016/j.carbpol.2017.06.107 
Dupont AL, Lavédrine B, Cheradame H (2010) Mass deacidification and reinforcement of papers and books VI - Study of aminopropylmethyldiethoxysilane treated papers. Polymer Degradation and Stability. 95:2300-2308.https://doi.org/:10.1016/j.polymdegradstab.2010.09.002

Erhardt D, \& Mecklenburg, M. F. (1995) Accelerated vs natural aging: effect of aging conditions on the aging process of cellulose. . MRS Online Proceeding Library Archive. 352:352.https://doi.org/:10.1557/PROC-352-247

Fan H, Guo M (2018) The Preservation and Repair of Ancient Books. China Pulp and Paper. 8:6165.https://doi.org/:10.11980/j.issn.0254-508X.2018.08.011

Feiertag P, Albert, M., Ecker - Eckhofen, E. - M., Hayn, G., Hönig, H., Oberwalder, H.W., Saf, R., Schmidt, A., Schmidt, O. and Topchiev, D. (2003) Structural characterization of biocidal oligoguanidines. . Macromolecular Rapid Communications,. 24:567570.https://doi.org/:10.1002/marc.200390085

He B, Lin Q, Chang M, Liu C, Fan H, Ren J (2019) A new and highly efficient conservation treatment for deacidification and strengthening of aging paper by in-situ quaternization. Carbohydr Polym. 209:250-257.https://doi.org/:10.1016/j.carbpol.2019.01.034

Isca C, Di Maggio R, Pajares Collado N, Predieri G, Lottici PP (2018) The use of polyamidoamines for the conservation of iron-gall inked paper. Cellulose. 26:12771296.https://doi.org/:10.1007/s10570-018-2105-8

Jalali MR, Sobati MA (2017) Intensification of oxidative desulfurization of gas oil by ultrasound irradiation: Optimization using Box-Behnken design (BBD). Applied Thermal Engineering. 111:1158-1170.https://doi.org/:10.1016/j.applthermaleng.2016.10.015

Jia H, Hongli, Zhu, Yuchen, \& Chen, et al. (2013) Highly transparent and flexible nanopaper transistors. ACS Nano. 7(3):2106-2113.https://doi.org/:10.1021/nn304407r

Konkol NR, McNamara CJ, Hellman E, Mitchell R (2012) Early detection of fungal biomass on library materials. Journal of Cultural Heritage. 13:115119.https://doi.org/:10.1016/j.culher.2010.05.002

Kukharenko O et al. (2014) Promising low cost antimicrobial composite material based on bacterial cellulose and polyhexamethylene guanidine hydrochloride. European Polymer Journal. 60:247-254.https://doi.org/:10.1016/j.eurpolymj.2014.09.014

Li J, Ye Y, Xiao H, He B, Qian L (2017) Microwave Assisted Preparation of Antimicrobial Chitosan with Guanidine Oligomers and Its Application in Hygiene Paper Products. Polymers (Basel). 9https://doi.org/:10.3390/polym9120633

Liu K, Xu Y, Lin X, Chen L, Huang L, Cao S, Li J (2014) Synergistic effects of guanidine-grafted CMC on enhancing antimicrobial activity and dry strength of paper. Carbohydr Polym. 110:382-387.https://doi.org/:10.1016/j.carbpol.2014.03.086

Manetti F et al. (2009) Synthesis of new linear guanidines and macrocyclic amidinourea derivatives endowed with high antifungal activity against Candida spp. and Aspergillus spp. J Med Chem. 52:7376-7379.https://doi.org/:10.1021/jm900760k

Mathurin YK, Koffi-Nevry R, Guehi ST, Tano K, Oule MK (2012) Antimicrobial activities of polyhexamethylene guanidine hydrochloride-based disinfectant against fungi isolated from 
cocoa beans and reference strains of bacteria. J Food Prot. 75:11671171.https://doi.org/:10.4315/0362-028X.JFP-11-361

Oule MK et al. (2008) Polyhexamethylene guanidine hydrochloride-based disinfectant: a novel tool to fight meticillin-resistant Staphylococcus aureus and nosocomial infections. J Med Microbiol. 57:1523-1528.https://doi.org/:10.1099/jmm.0.2008/003350-0

Peng Y, Duan C, Elias R, Lucia LA, Fu S (2018) A new protocol for efficient and high yield preparation of cellulose nanofibrils. Cellulose. 26:877-887.https://doi.org/:10.1007/s10570$\underline{018-2112-9}$

Peydayesh M, Bagheri M, Mohammadi T, Bakhtiari O (2017) Fabrication optimization of polyethersulfone (PES)/polyvinylpyrrolidone (PVP) nanofiltration membranes using BoxBehnken response surface method. RSC Advances. 7:2499525008.https://doi.org/:10.1039/c7ra03566g

Piantanida G, Pinzari F, Montanari M, Bicchieri M, Coluzza C (2006) Atomic Force Microscopy Applied to the Study of Whatman Paper Surface Deteriorated by a Cellulolytic Filamentous Fungus. Macromolecular Symposia. 238:92-97.https://doi.org/:10.1002/masy.200650613

Pinto F, Maillard JY, Denyer SP, McGeechan P (2010) Polyhexamethylene biguanide exposure leads to viral aggregation. J Appl Microbiol. 108:1880-1888.https://doi.org/:10.1111/j.1365$\underline{2672.2009 .04596 . x}$

Piovesan C, Fabre-Francke I, Paris-Lacombe S, Dupont A-L, Fichet O (2018) Strengthening naturally and artificially aged paper using polyaminoalkylalkoxysilane copolymer networks. Cellulose. 25:6071-6082.https://doi.org/:10.1007/s10570-018-1955-4

Ponce-Jimenez MDP, Toral, L. D. , \& Fornue, E. D. ( 2003) Antifungal protection and sizing of paper with chitosan saltsand cellulose ethers. part 1, physical effects. Journal of the American Institute for Conservation. 41(3):243.https://doi.org/:10.2307/3179921

Qian L, Guan Y, He B, Xiao H (2008) Modified guanidine polymers: Synthesis and antimicrobial mechanism revealed by AFM. Polymer. 24712475.https://doi.org/:10.1016/j.polymer.2008.03.042

Rabelo SC, Andrade RR, Maciel Filho R, Costa AC (2014) Alkaline hydrogen peroxide pretreatment, enzymatic hydrolysis and fermentation of sugarcane bagasse to ethanol. Fuel. 136:349357.https://doi.org/:10.1016/j.fuel.2014.07.033

Salama A, Hasanin M, Hesemann P (2020) Synthesis and antimicrobial properties of new chitosan derivatives containing guanidinium groups. Carbohydr Polym. 241:116363.https://doi.org/:10.1016/j.carbpol.2020.116363

Sarantopoulou E, Kollia Z, Gomoiu I (2006) Preventing biological activity of Ulocladium sp spores in artifacts using 157-nm laser. Applied Physics A. 83:663-668.https://doi.org/:10.1007/s00339$\underline{006-3554-8}$

Simona Margutti GC, Paolo Calvini,Enrico Pedemonte (2001) Hydrolytic and oxidative degradation of paper. Restaurator. 22(2):67-83.https://doi.org/:10.1515/REST.2001.67

Thakkar P, Passic, Zhu, Kholodovych, \& Welsh, et al. (2009) Specific interactions between the viral coreceptor cxcr4 and the biguanide-based compound nb325 mediate inhibition of human 

):631-638.

514 Wang L (2006) Ancient Book Restoration_ — the Burden is Heavy and the Road Ahead is Long. 515 Journal of Library and Information Sciences in Agriculture. 08:8990.https://doi.org/:10.13998/j.cnki.issn1002-1248.2006.08.031

Wang L, Guo H, Chen X, Chen Q, Wei X, Ding Y, Zhu B (2015) Optimization of the catalytic hydrogenation of terebinth by a Ni-based catalyst. Catalysis Science \& Technology. 5:33403351.https://doi.org/:10.1039/c4cy01704h

Wei D, Li Z, Wang H, Liu J, Xiao H, Zheng A, Guan Y (2017) Antimicrobial paper obtained by dipcoating with modified guanidine-based particle aqueous dispersion. Cellulose. 24:39013910.https://doi.org/:10.1007/s10570-017-1386-7

Xiao G, Wang Y, Zhang H, Zhu Z, Fu S (2020) Dialdehyde cellulose nanocrystals act as multi-role for the formation of ultra-fine gold nanoparticles with high efficiency. Int J Biol Macromol. 163:788-800.https://doi.org/:10.1016/j.ijbiomac.2020.07.057

Yi X, Yan Z, Zhang M, Long K (2017) Study on the Consolidation of Aged Literature's Paper by Nanocellulose. Journal of Cellulose Science and Technology. 25https://doi.org/:10.16561/j.cnki.xws.2017.03.05

Yuri Kobayashi TS, \& Akira Isogai (2015) Aerogels with 3d ordered nanofiber skeletons of liquidcrystalline nanocellulose derivatives as tough and transparent insulators. Angewandte Chemie International Edition. 53(39):10253-10253.https://doi.org/:10.1002/anie.201406635

Zeng X, Fu, S. , Retulainen, E. , \& Heinemann, S. (2012) Fibre deformations induced by different mechanical treatments and their effect on zero-span strength. Nordic Pulp and Paper Research Journal. 27(2):335-342.https://doi.org/:10.3183/NPPRJ-2012-27-02-p335-342

Zhang M (2020) Research of Paper Documents Reinforcement Technology at Home and Abroad. China Pulp and Paper. v.39:76-82.https://doi.org/:10.11980/j.issn.0254-508X.2020.03.011

Zhang W et al. (2016) Paper reinforced with regenerated cellulose: a sustainable and fascinating material with good mechanical performance, barrier properties and shape retention in water. Journal of Materials Chemistry A. 4:17483-17490.https://doi.org/:10.1039/c6ta07681e

Zhang Y, Jiang, J. , \& Chen, Y. (1999) Synthesis and antimicrobial activity of polymeric guanidine and biguanidine salts. . Polymer. 40(22):6189-6198.https://doi.org/:10.1016/S0032$\underline{3861(98) 00828-3}$

Zhong LX, Peng XW, Yang D, Cao XF, Sun RC (2013) Long-chain anhydride modification: a new strategy for preparing xylan films. J Agric Food Chem. 61:655661.https://doi.org/:10.1021/jf304818f 


\section{Figures}

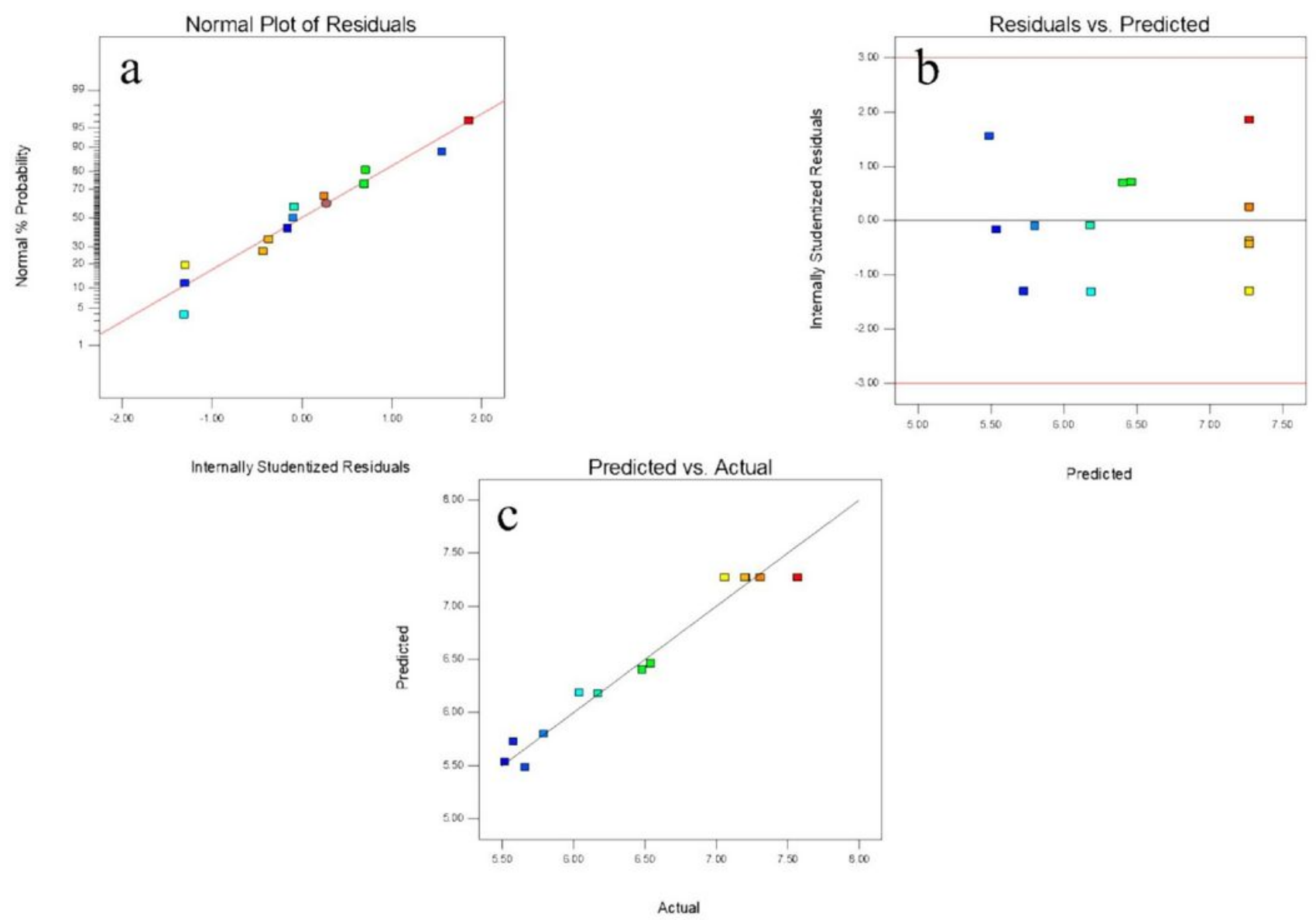

Figure 1

Evaluation of RSM correlation for the paper's tearing index ( $\mathrm{mN} \otimes \mathrm{m} 2 / \mathrm{g}$ ). (a) The normal probability distribution of residuals, (b) Distribution of residual versus predicted values, and (c) Chart of predicted value and actual value 

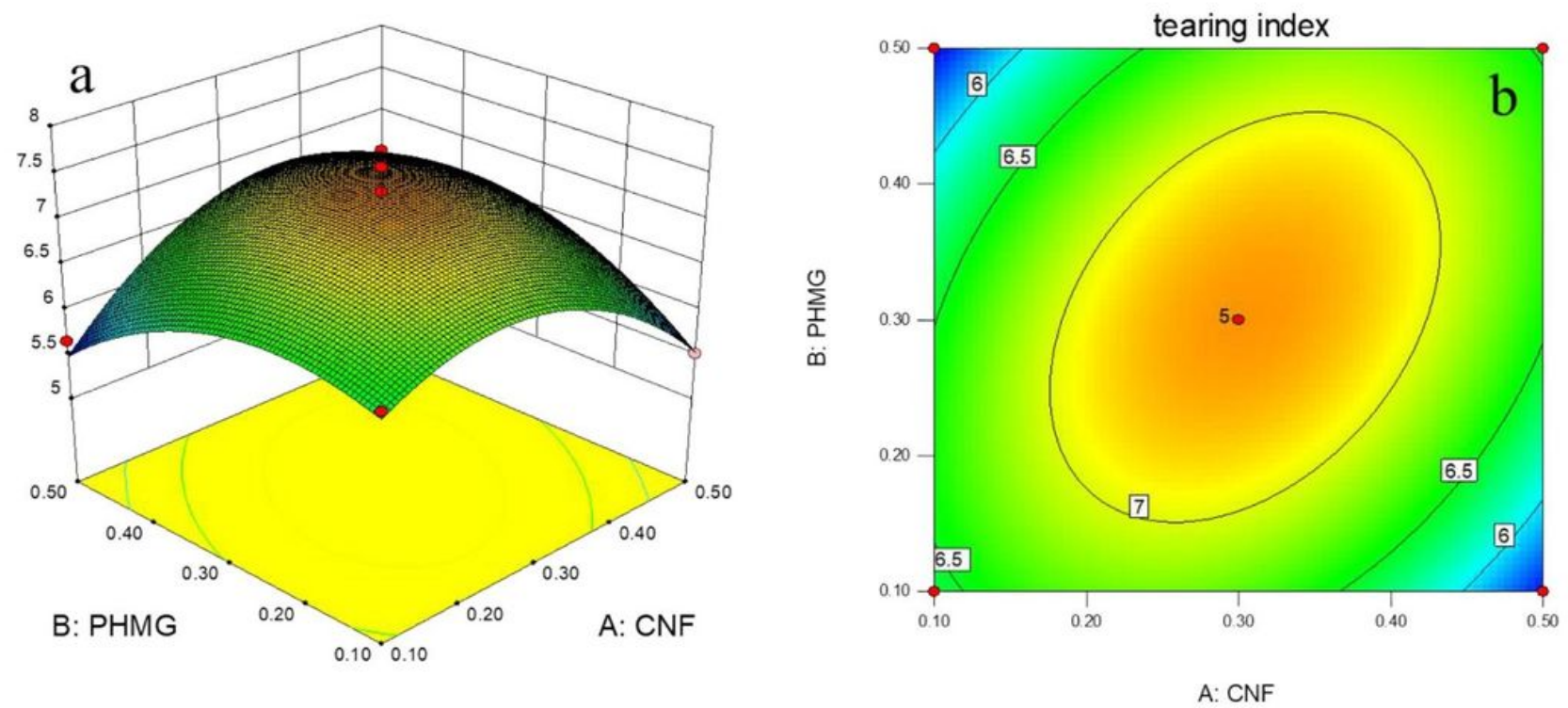

Figure 2

The interaction between the concentration of CNCS and the density of PHMG on the enhancement of tearing strength of paper samples 


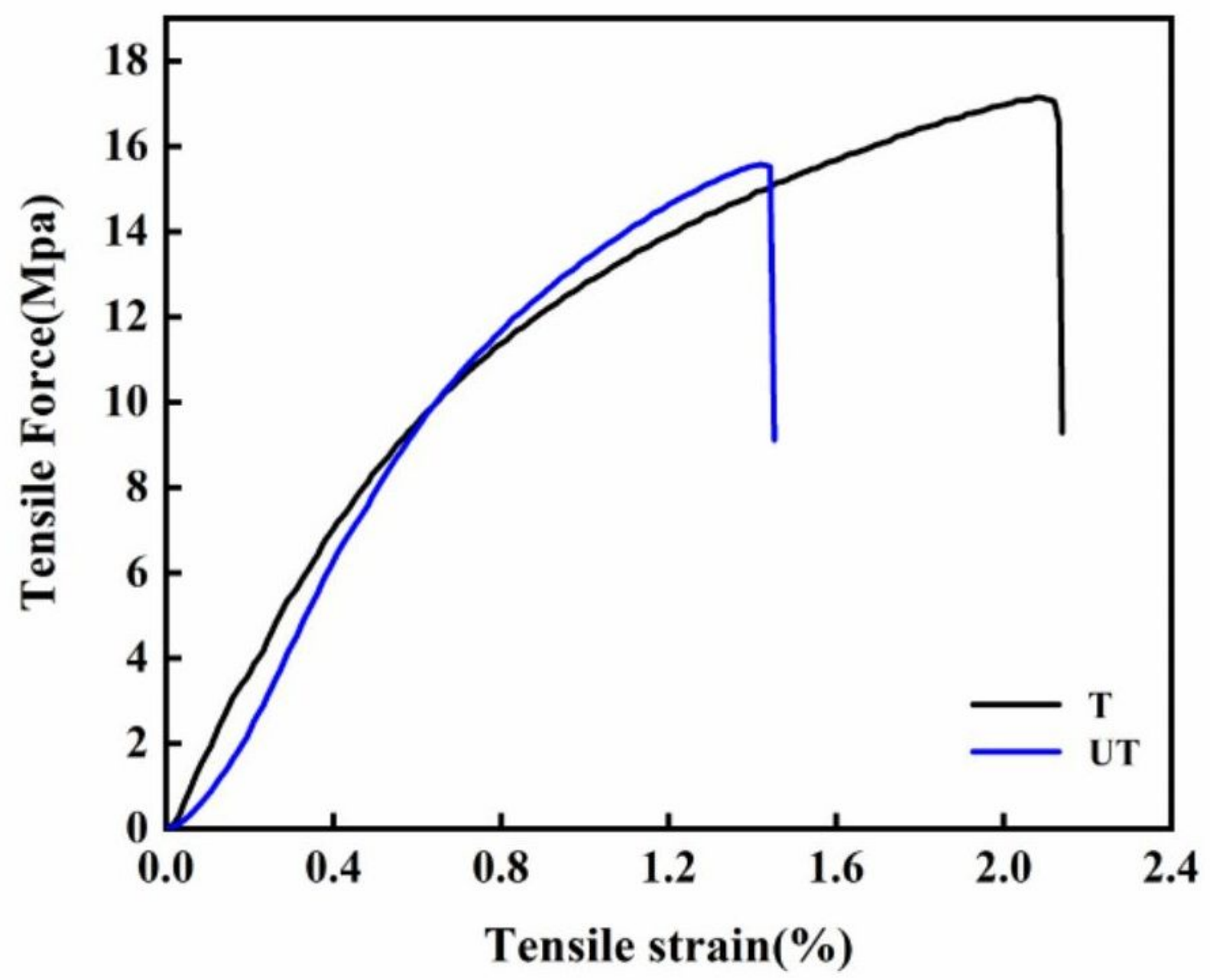

Figure 3

Tensile force vs. percentage tensile strain for treated and untreated paper 
A
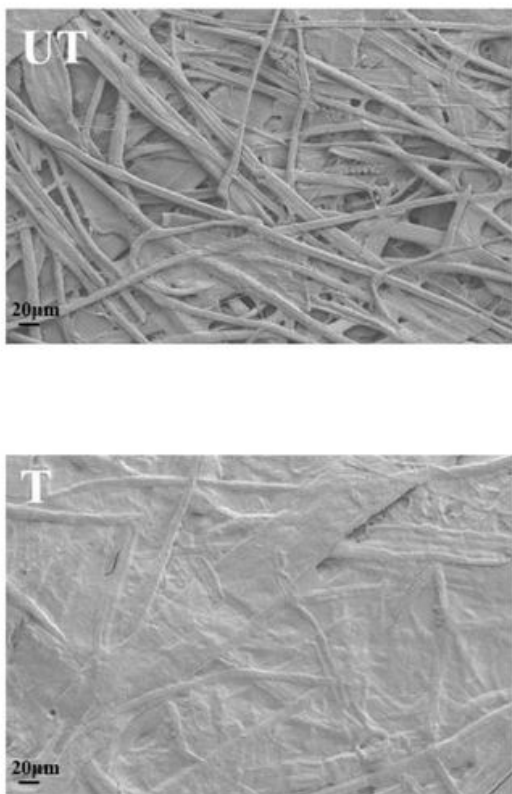

B

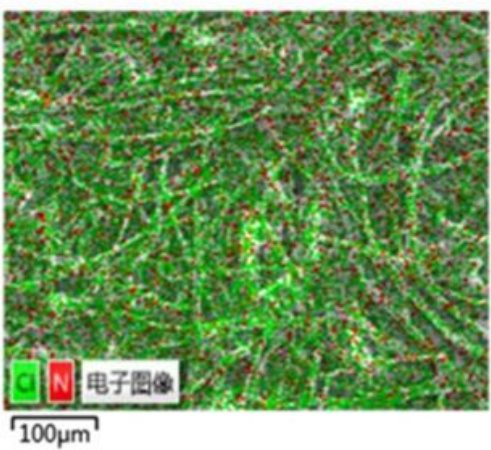

$\mathrm{Cl} \mathrm{K \alpha 1}$

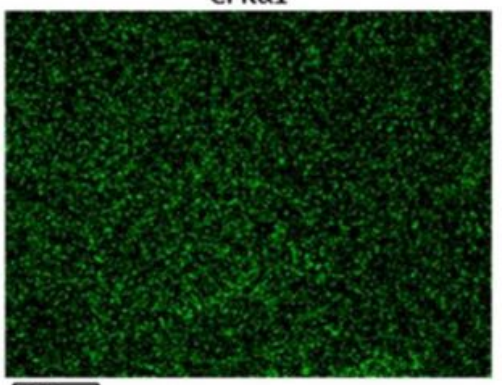

$\widehat{100 \mu \mathrm{m}}$
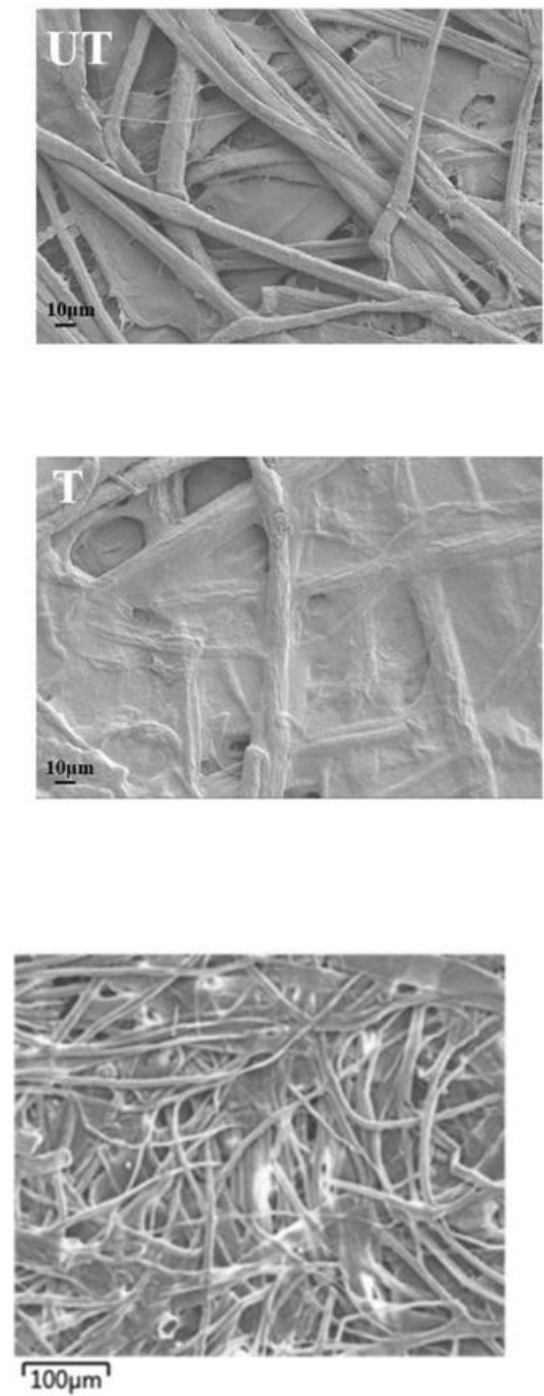

N K $\alpha 12$

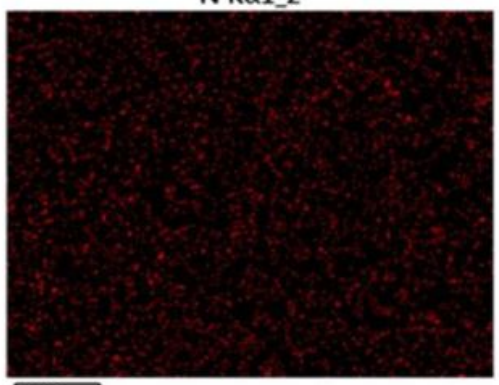

$\overparen{100 \mu \mathrm{m}}$
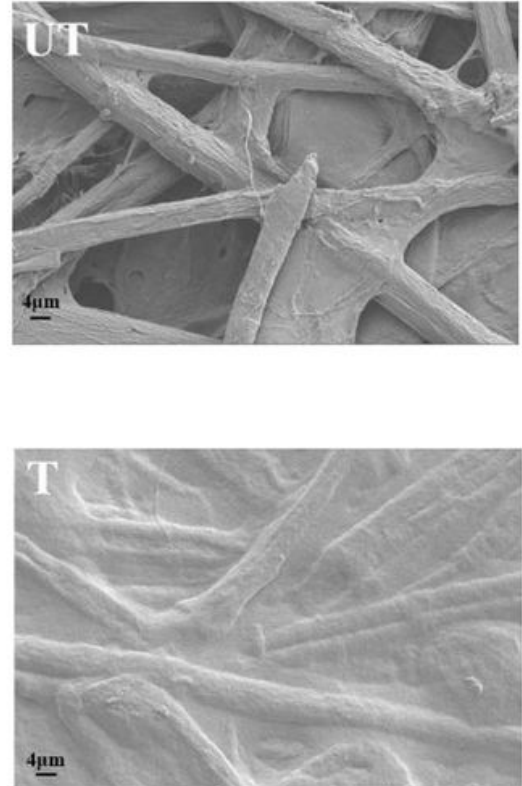

Figure 4

(a) SEM images of these paper samples treated (T) and untreated (UT) (b) SEM-EDS images of the paper sample treated by CNCS/PHMG 


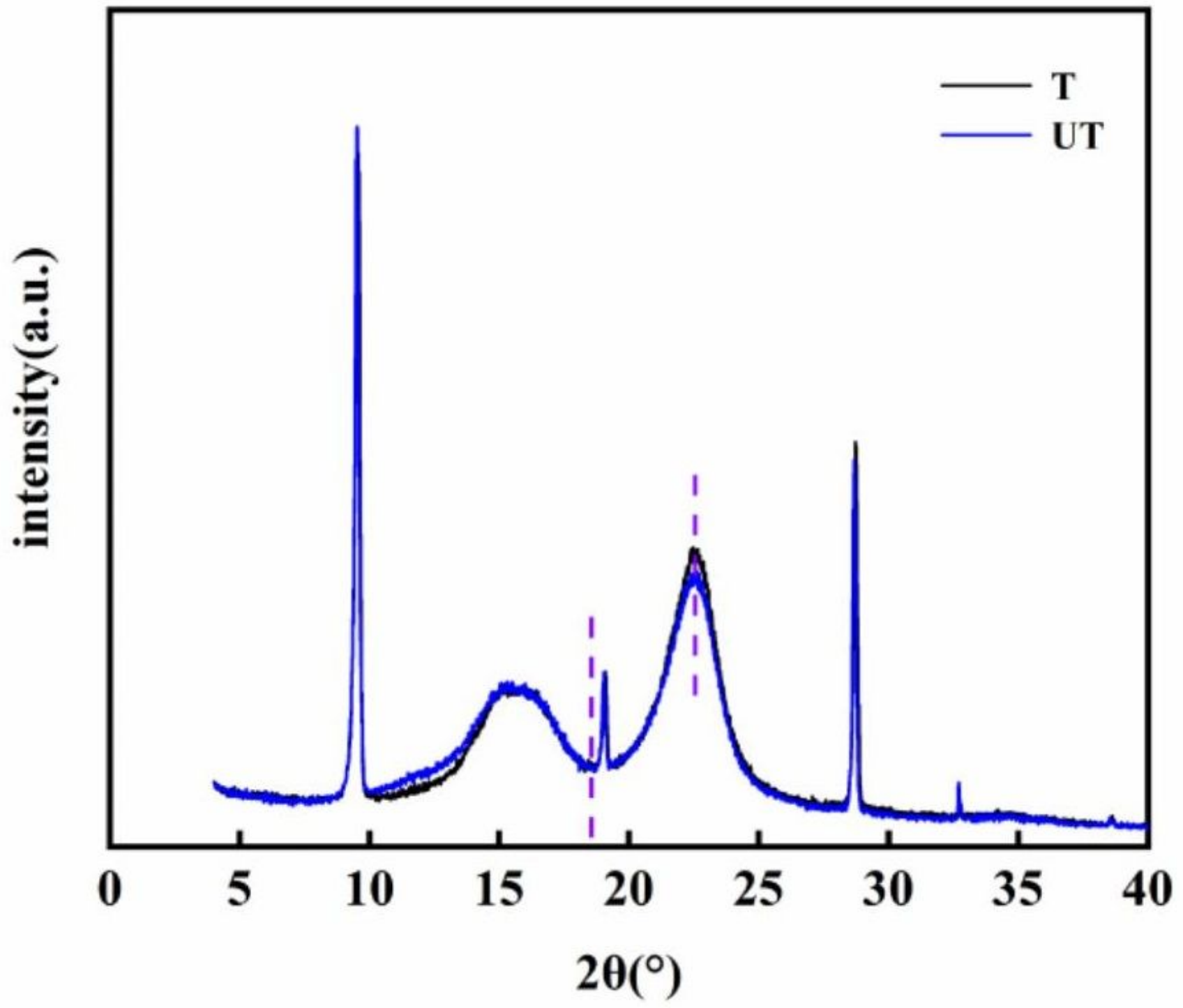

Figure 5

XRD images of treated $(\mathrm{T})$ and untreated (UT) paper samples 

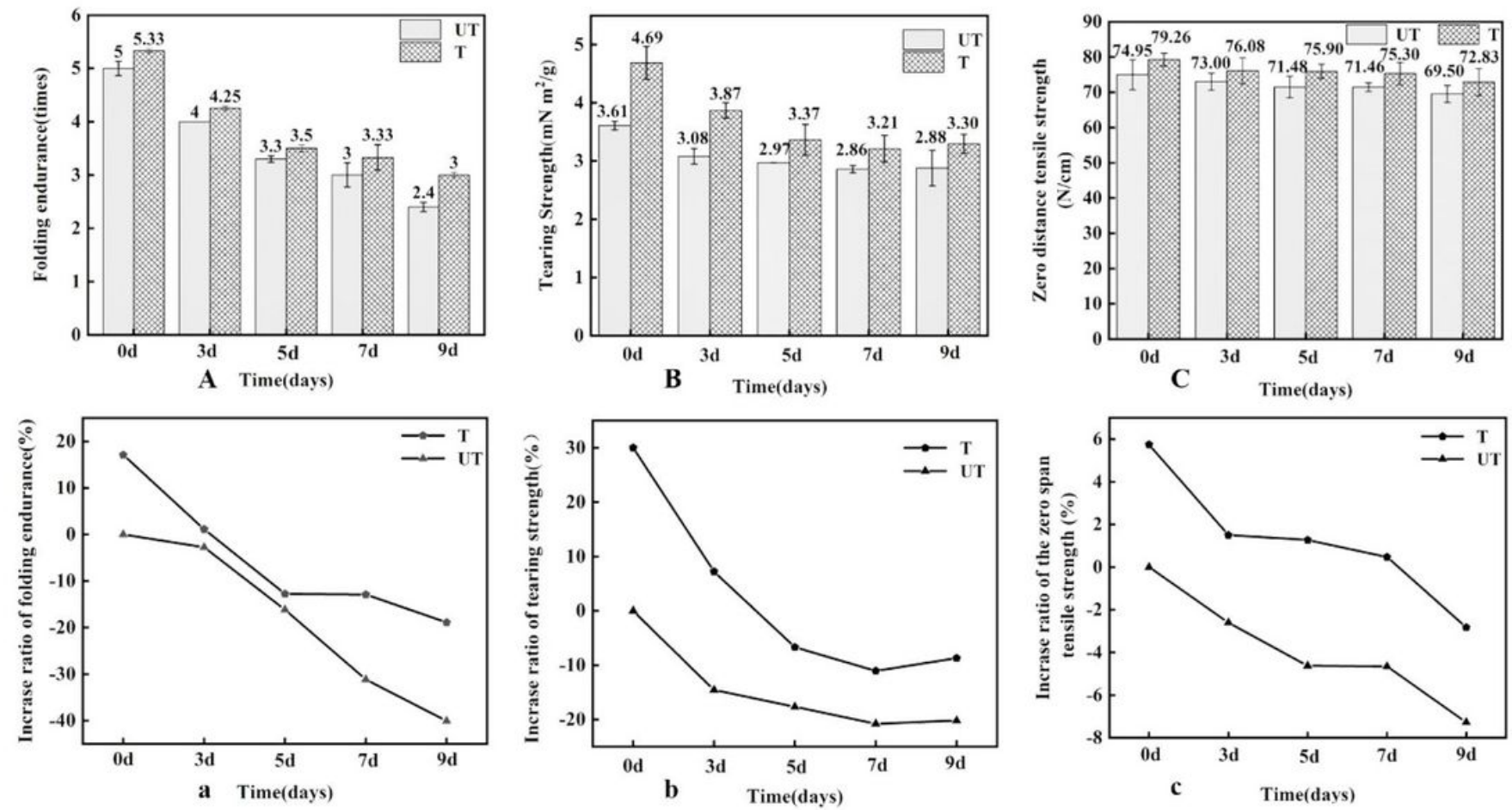

\section{Figure 6}

The comparison of treated and untreated paper samples after aging on folding endurance (A); tearing index(B) and zero-span tensile strength(C); Enhanced ratio comparison: folding endurance (a), tearing strength(b) and zero-distance tensile strength(c) 


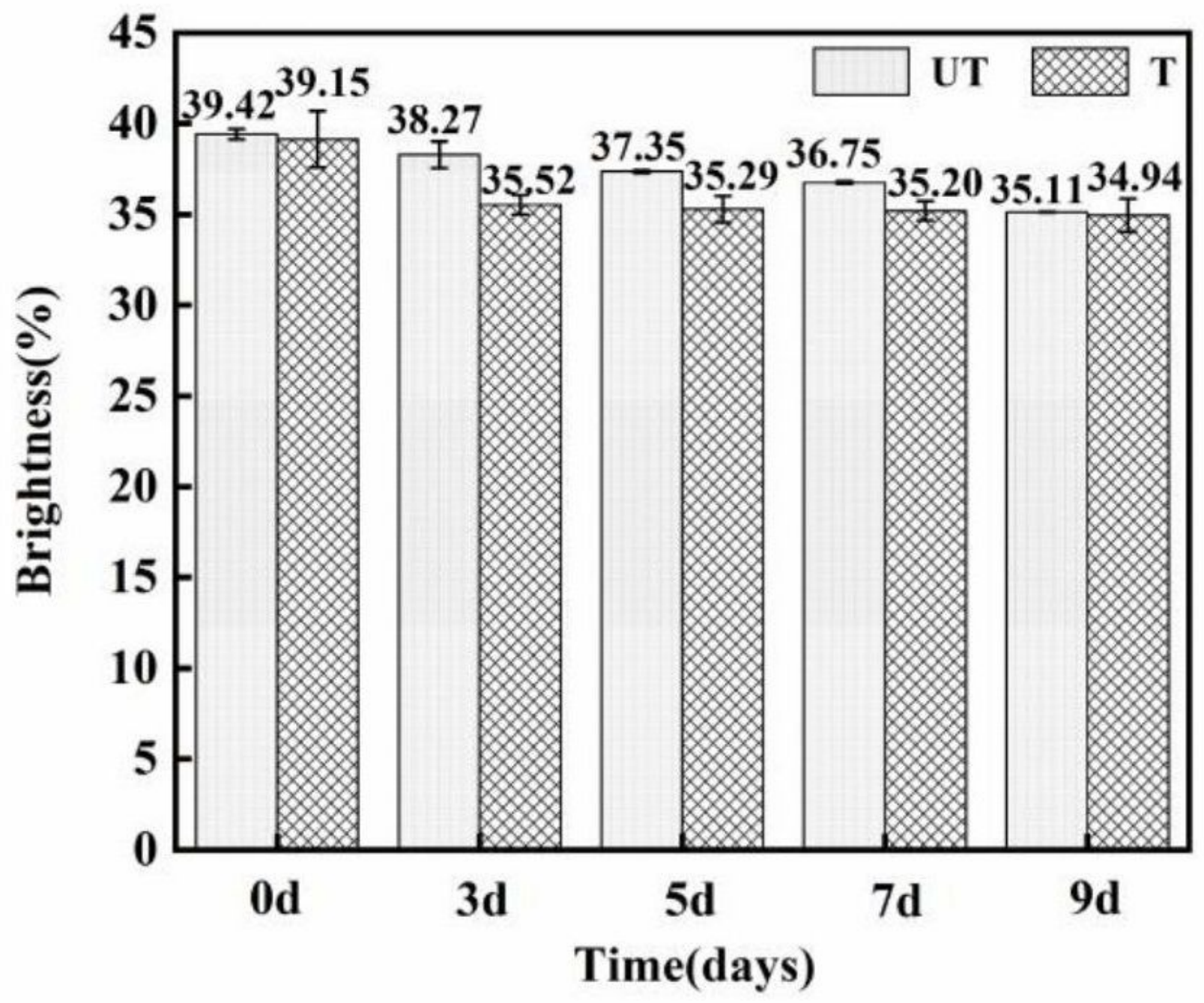

Figure 7

The brightness of treated and untreated paper samples after aging 

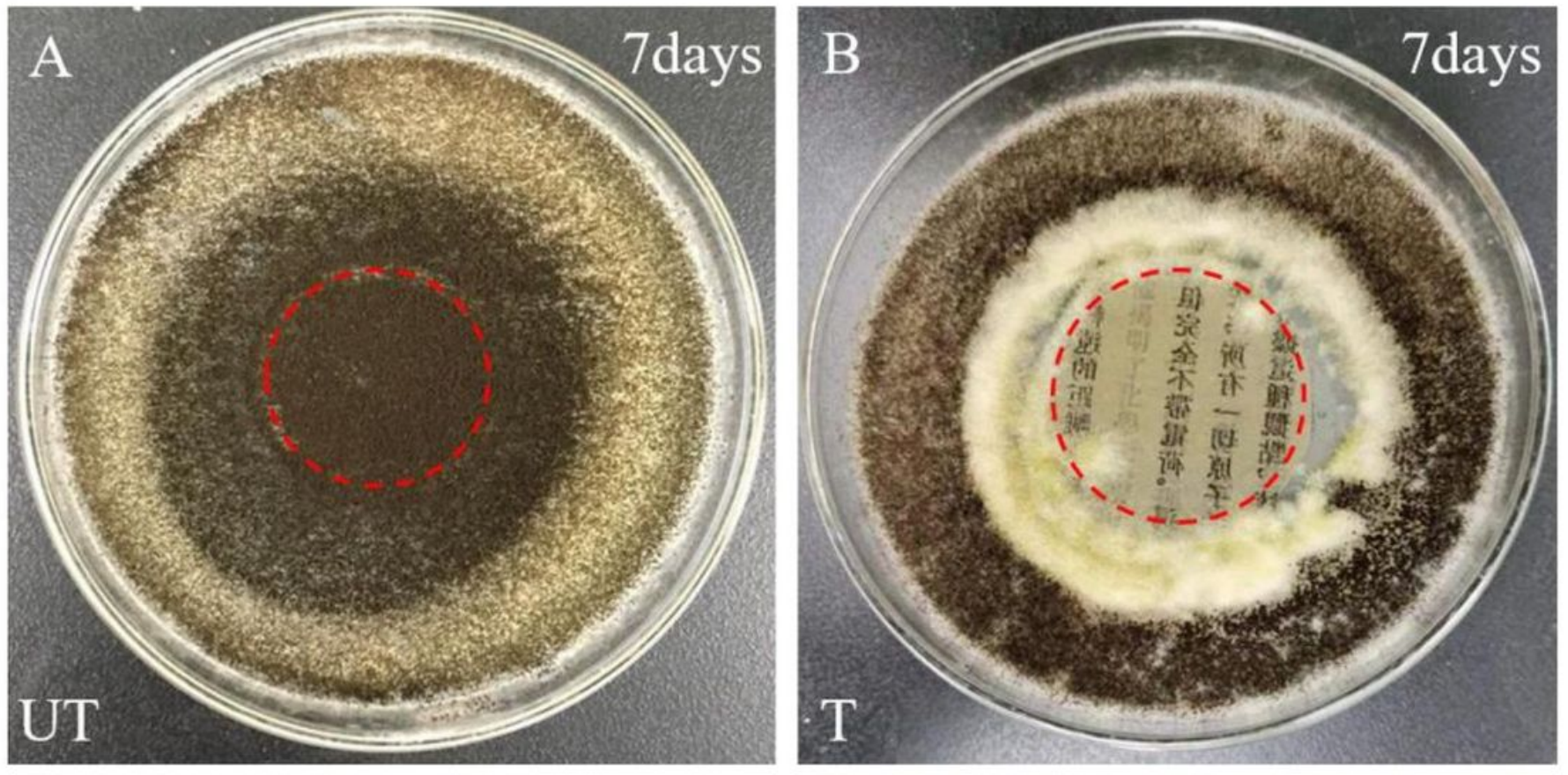

Figure 8

The 7-days anti-Aspergillus Niger effect of paper samples:(1) A UT (untreated) (2) B T (treated) 

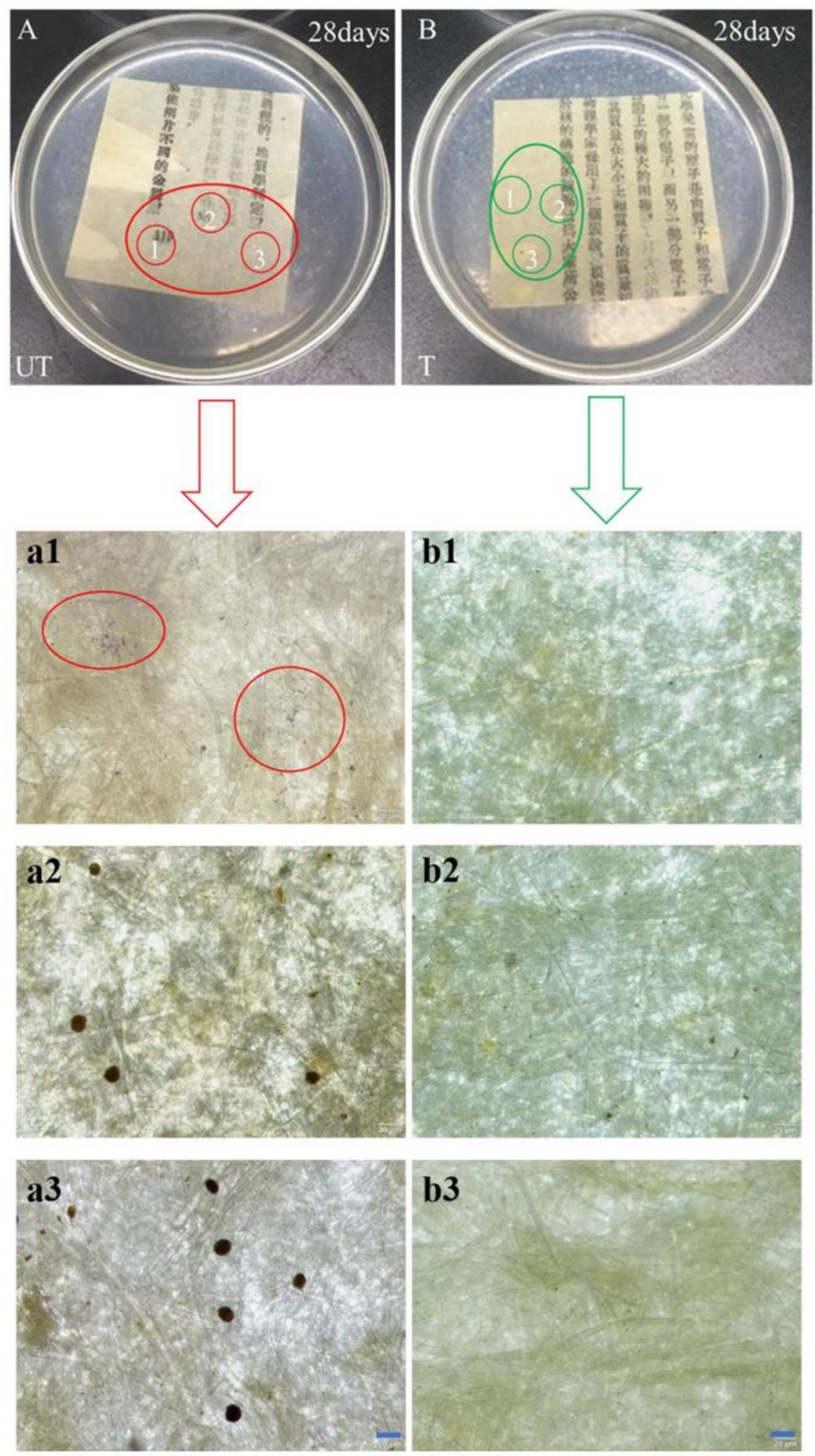

Figure 9

The 28-days anti- mixed mold effect of paper samples:(1) A untreated (2)B treated, and the surface photo of the paper observed by polarized light microscope $\ s c a l e ~ b a r=20 \mu \mathrm{m} \rrbracket$

\section{Supplementary Files}


This is a list of supplementary files associated with this preprint. Click to download.

- SupplementaryMaterial.docx 